Participants' Experiences of a Receptive Music Therapy Intervention that Incorporates Raga: An Interpretative Phenomenological Analysis.

\title{
Stephen Venkatarangam
}

A Thesis

in

The Department

of

Creative Arts Therapies

Presented in Partial Fulfillment of the Requirements

for the Degree of Masters of Arts (Creative Arts Therapies, Music Therapy Option) Concordia University

Montreal, Quebec, Canada

September 2017

(C) Stephen Venkatarangam, 2017 


\section{CONCORDIA UNIVERSITY}

\section{School of Graduate Studies}

This is to certify that the thesis prepared

By: $\quad$ Stephen Venkatarangam

Entitled: Participants' Experiences of a Receptive Music Therapy Intervention that Incorporates Raga: An Interpretative Phenomenological Analysis.

and submitted in partial fulfillment of the requirements for the degree of

\section{Master of Arts (Creative Arts Therapies, Music Therapy Option)}

Complies with the regulations of the University and meets the accepted standards with respect to originality and quality.

Signed by the final Examining Committee:

Chair

Sandra Curtis

Examiner

Guylaine Vaillancourt

Examiner

Yehudit Silverman

Supervisor

Sandra Curtis

Approved by

Yehudit Silverman, Chair, Department of Creative Arts Therapies

2017

Rebecca Taylor Duclos, Dean, Faculty of Fine Arts 


\begin{abstract}
Participants' Experiences of a Receptive Music Therapy Intervention that Incorporates Raga: An Interpretative Phenomenological Analysis.
\end{abstract}

\title{
Stephen Venkatarangam
}

Indian musicians, scholars, and music therapists have explored the use of raga for many years, with music therapists recommending its use in meditation, visualization, and clinical improvisation. Little formal research, however, exists concerning the use of raga in clinical settings with clients unfamiliar with this style of music. By means of Interpretative Phenomenological Analysis, this qualitative research explored the lived experiences of 3 participants unfamiliar with raga within a live-receptive raga intervention. The primary method of data collection was semi-structured interviews. The following overarching themes emerged through coding and analysis of the interviews: (a) initial awareness of sensory stimulation/environment; (b) pre-contextual thought processes as inherent to the experience; (c) raga as a trusted guide; the development of a "cognitive holding space" through music; (d) emotional and physiological changes throughout the musical movement; and (e) preferred duration of experience. These overarching themes as well as subsidiary themes were explored at a group level while accounting for the unique and rich differences of the participants' individual experiences. The study provides information to further the dialogue concerning integration of raga within a music therapy context. Particular receptive interventions that may enrich the therapeutic experiences of populations of diverse and non-specialized backgrounds are suggested. 


\section{ACKNOWLEDGEMENTS}

I gratefully acknowledge:

The participants in the study, for their willingness to share their rich experiences. My advisor Dr. Sandi Curtis for her guidance and insight throughout the many steps of this research.

The Music Therapy Faculty at Concordia University, including Dr. Laurel Young, Dr. Guylaine Vaillancourt, and Deborah Seabrook, for their feedback, guidance, and encouragement during the construction of this research.

My ever so patient and caring sitar teachers through the years: Uwe Neumann, Ustad Shahid Parvez, and Seema Gulati.

The professors in other faculties who inspired me to pursue this avenue of research, including Dr. David Pare, Dr. Rosemary Mountain, and Dr. Rebecca J. Lloyd.

Dr. Sumathy Sundar for her vital contribution to this area of research and her directions in navigating the complex world of raga in music therapy.

Annabelle Brault for her invaluable help during the raga experience.

My parents and family for their support and encouragement.

My music therapy peers at Concordia for their hours of peer supervision during an intensive few years. 


\section{Table of Contents}

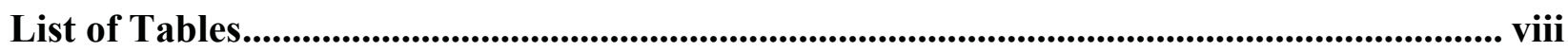

Chapter 1. Introduction ...........................................................................................................................1

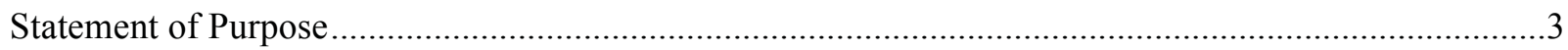

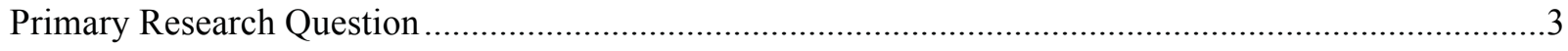

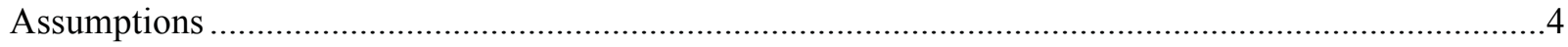

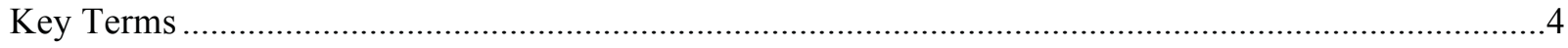

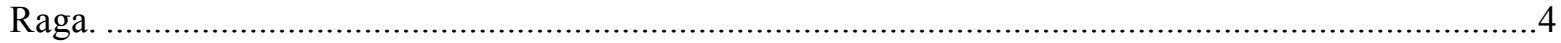

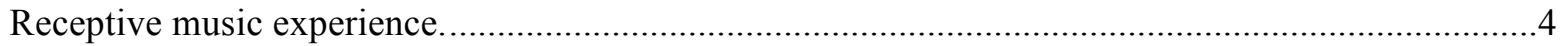

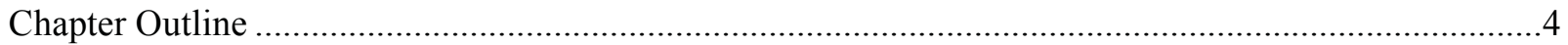

Chapter 2: Literature Review ..........................................................................................................6

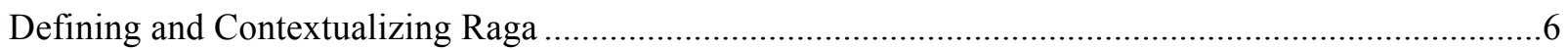

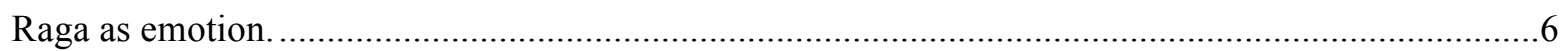

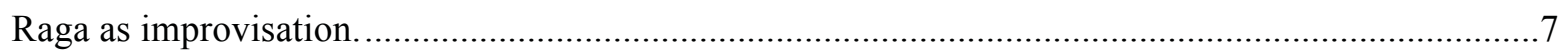

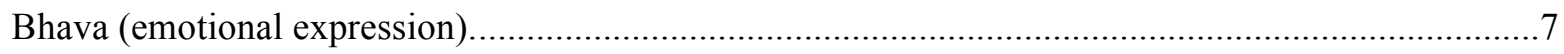

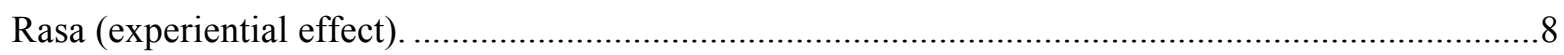

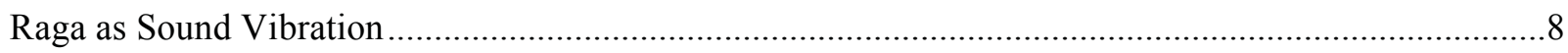

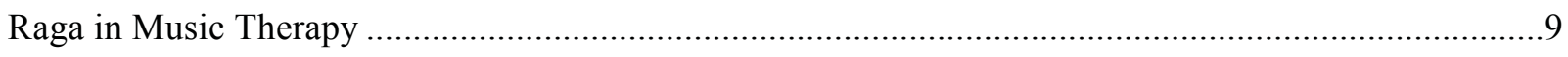

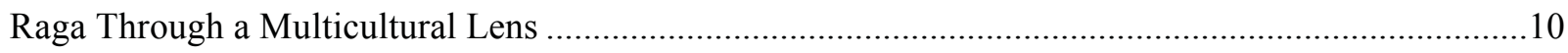

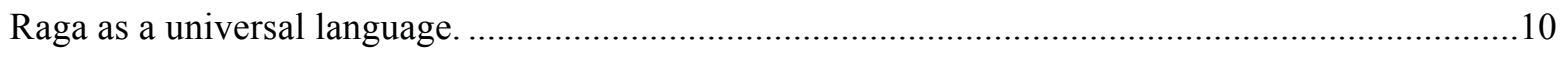

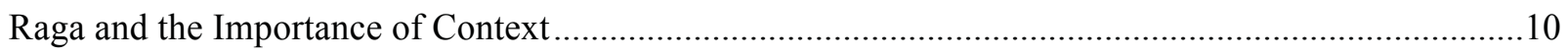

Potential Applications of Raga in Cross-Cultural Settings .............................................................11

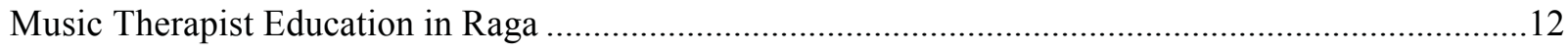

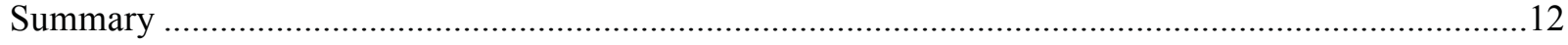

Chapter 3: Methodology .......................................................................................................14

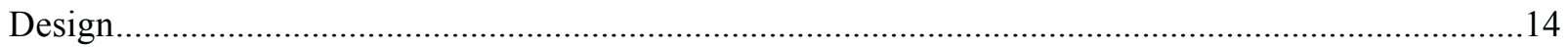

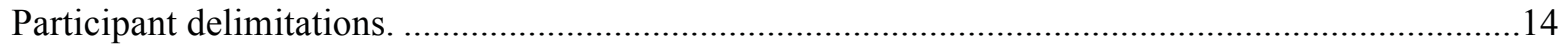

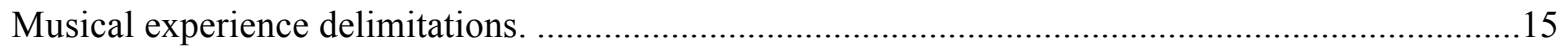

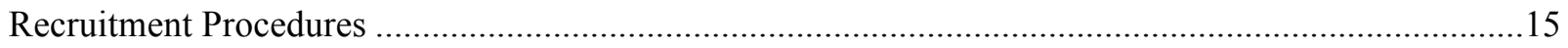

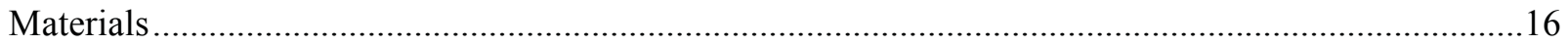

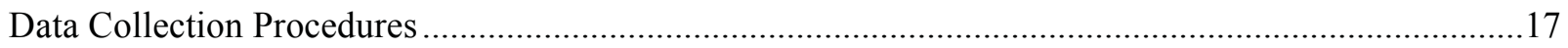

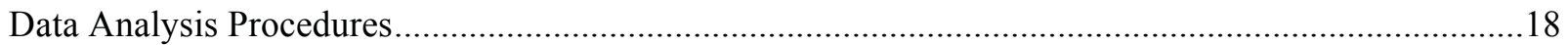




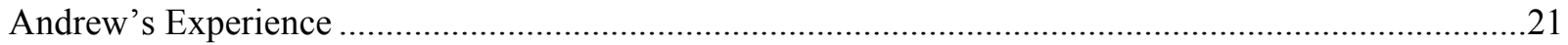

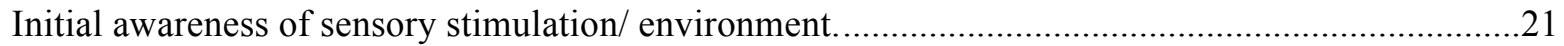

Pre/ post-contextual thought processes as inherent to the experience. ............................................21

Raga as trusted guide; the development of a "cognitive holding space" through music....................22

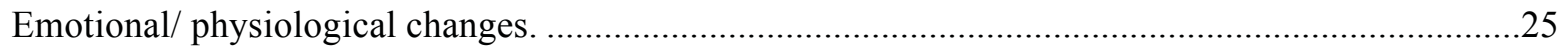

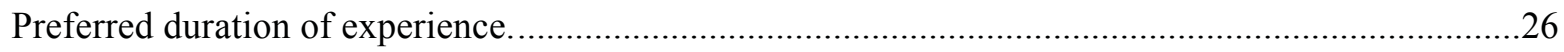

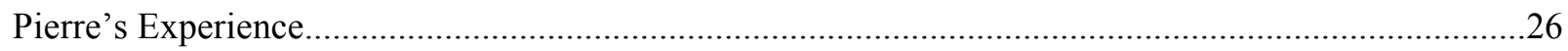

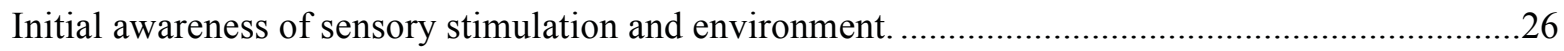

Pre/post-contextual thought processes as inherent to the experience. .................................................27

Raga as trusted guide; the development of a "cognitive holding space" through music....................28

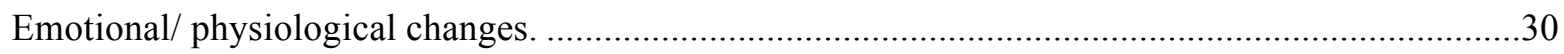

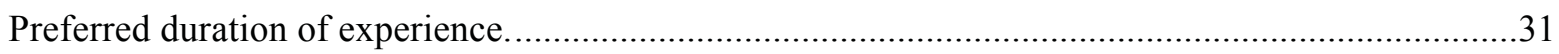

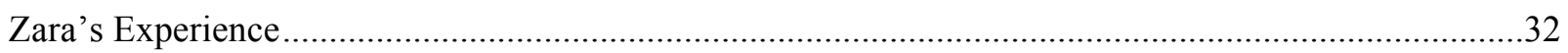

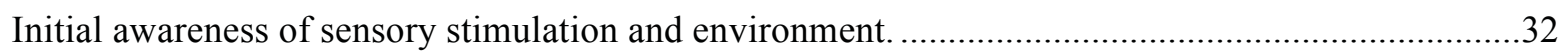

Pre/ post-contextual thought processes as inherent to the experience. ............................................33

Raga as trusted guide; the development of a "cognitive holding space" through music....................34

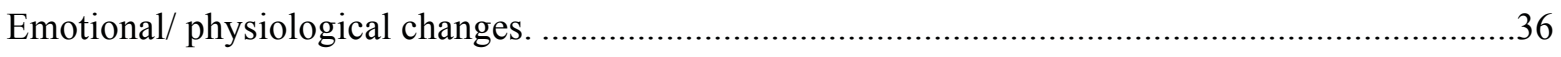

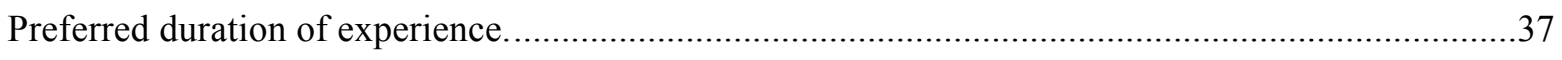

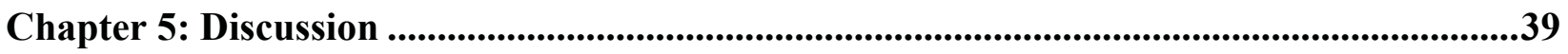

Pre/Post-Contextual Thought Processes as Inherent to the Experience ..................................................39

Raga as Trusted Guide; The Development of a "Cognitive Holding Space" Through Music.................41

Musical safety while being allowed to mentally explore ...............................................................41

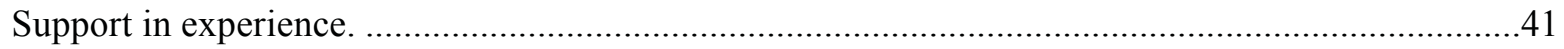

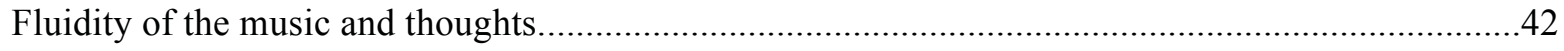

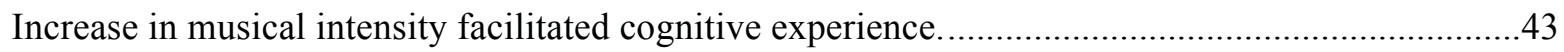

Music distancing oneself from present/physical reality................................................................4

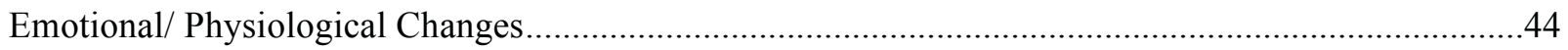

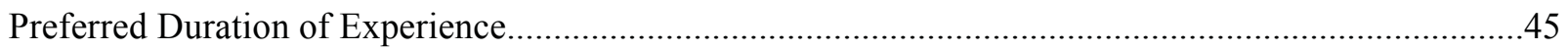

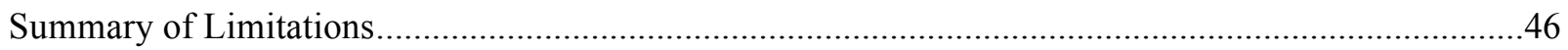

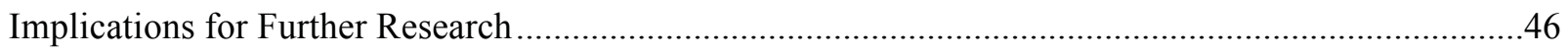

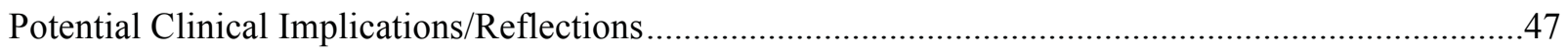

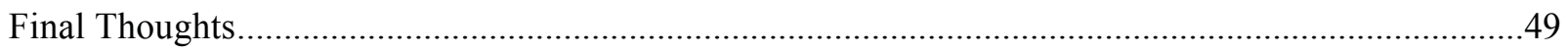




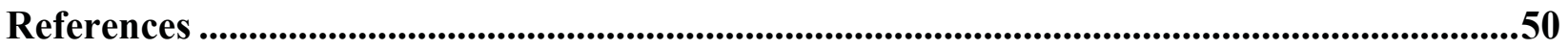

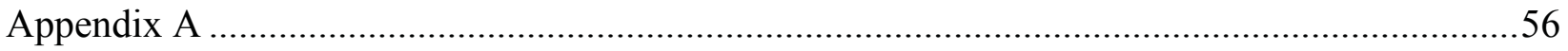

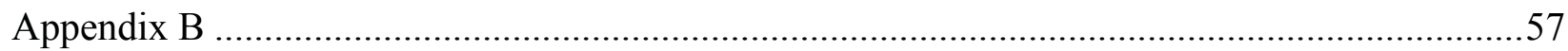

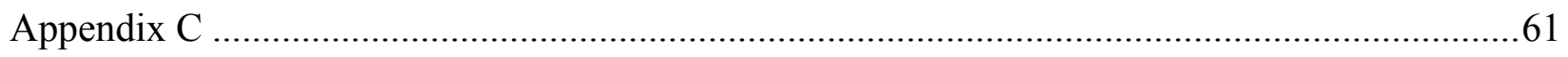

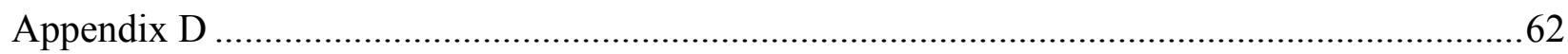

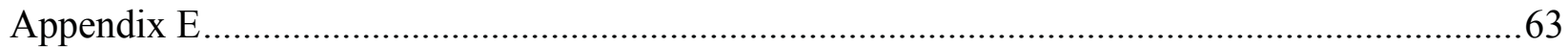




\section{List of Tables}

Table 1: Demographic Information of Study Participants ..................................................................16

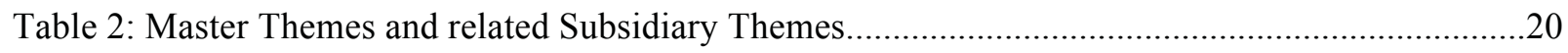




\section{Chapter 1. Introduction}

Raga, the classical musical system of India, can be considered a sequence of tonal variations that have particular qualities connected to emotions, color, and time of day (Forney \& Machlis, 2007). The music, most innately expressed and inspired by the voice (Rao, 2014), can be played to some manner on any tonal musical instrument. Since shortly after the Vedic period of 1750-500 BCE, Indian musicians and scholars have explored the healing power of raga in devotional music (Sundar, 2005; 2007), community experiences (Cook \& Cook, 1997), personal ritual, and professional performance (Ruckert, Khan, \& Khan, 2009). One might speculate as to how this music might translate to cross-cultural settings, and more specifically when used in Western music therapy practice. Music therapists in Western settings have advocated for the use of raga in meditation and visualization (Moreno, 1988); however, little formal research to date has explored how raga might be used with music therapy clients who are not familiar with this genre. My personal relationship to raga and my interest in its potential for clinical use are rooted in my own experiences as a performer, listener and music therapist.

I was formally introduced to raga later in life through my extensive study of the sitar.

Although I am of East Indian decent and was initially exposed to this music through cultural community events, growing up in Canada, I was encouraged and immersed in the prevalent discourse of Western classical and popular music. Although I was touring, and writing music in various projects, playing various instruments, as well as later pursuing a degree in Western classical voice; my introduction to the sitar, and later to studying raga, was inadvertently through my growing interest in the music of the Western artists who incorporated elements of raga into their own. This included The Beatles' incorporation of the sitar and raga in "Within you without you" (Harrison, 1967, track 8), the Mahavishnu Orchestra's incorporation of raga with Jazz/Rock fusion in 'Miles beyond' (McLaughlin, 1973, track 2); as well as Philip Glass' incorporation of sitar and raga with Western classical music in "Ragas in Minor Scale" (Glass, 1990, track 4). While the Indian sitar is sometimes used in other genres (as previously illustrated), it has traditionally been used in raga music (Miner, 2004). Consequently, when I began learning sitar from a recognized guru, I concurrently began a lifelong study of the vast musical tradition of raga.

I noticed during my own practice, when playing on stage, and when listening to other players, that raga has a transformative effect on myself: it elicits feelings of relaxed elevation and 
mindful introspection. I began to wonder how other people less accustomed to this genre might respond to it. My personal experiences, knowledge, and curiosity led me to introduce live receptive raga sitar experiences into clinical music therapy contexts, including a mental health outpatient hospital, a residence with geriatric clients, and at a community day center for adults with intellectual disabilities. When I played Indian improvised raga in clinical music therapy receptive experiences, several clients with mental health problems, who had never listened to this music, indicated that they felt balanced, calm and peaceful afterwards. In my geriatric work, clients had diverse experiences ranging from that of euphoria, to wooziness and drowsiness. Furthermore, in the community center where I worked with clients with intellectual disabilities, one client who had never heard a sitar before reported the experience as "beautiful" and requested this experience as an opening ritual for each session. I also facilitated receptive raga experiences in non-music therapy contexts, including day camps for children, and support groups for individuals with Alzheimer's Disease (AD). Some patients living with AD remarked on the "timeless feeling" of the music, while others had vivid memories of seeing Ravi Shankar at Woodstock in the 1960's. On one occasion, when I was performing a raga intervention at a day camp, one child asked me, "Why did the music make me feel that way?" I recognized that these persons were being impacted by their experiences of raga and that their experiences were individual and complex, not easily described with one-word answers.

In Indian culture, it is believed that raga affects Rasa, or the emotional state of mind (Clayton, 2001). The ethnomusicologist Clayton (2001) noted that performers and scholars within and outside of India agree that the essence of raga cannot simply be defined by constructs such as timbre, scale and meter, but can only truly be defined through human experience.

Little formal research to date has investigated the emotional states of individuals during and after listening to ragas (Bowling, 2013). In one study, researchers found that individuals in India who listened to raga scored higher (i.e., exhibited lower states of depression) than those in the psychotropic control group. It should be noted that the groups were not assigned in a randomized manner and sample size was relatively small (Deshmukh, Sarvaiya, Seethalakshmi, \& Nayak, 2009). Subsequently, these results warrant further investigation (Deshmukh et al., 2009). Some research also indicates a cross-cultural potential for the application of raga. Two studies on cross-cultural investigations into the perception of music found that both experienced and non-experienced raga listeners from various cultures had similar perceptions of the emotional 
intent of particular South Indian and Western scales (Balkwill \& Thompson, 1999; Bowling, Sundararajan, Han, \& Purves, 2012). In addition, Moreno (1988) indicated that raga could be beneficial in music therapy cross-culturally when used in the context of receptive relaxation and visualization activities; this was based on his own experiences using raga with clients.

As a music therapist who has studied raga, I see great potential for incorporating it into my clinical work. Furthermore, other music therapists, if given the information and support that they need, could also use raga in their practice. This could lead to training in performance as well as enhancing cultural competencies in music therapy pedagogy. Raga has traditionally been used for healing for centuries; it is evident that there are cross-culturally shared perceptions of raga. However, in order to use raga effectively and appropriately in clinical contexts and to have a more complete understanding that captures the nuances, subtleties and richness of this experience, more research is needed. The current research is a foundational step in that an increased understanding of the lived experience of raga that takes place within a natural experiential context could lead to the knowledgeable incorporation of this genre into traditional music therapy approaches. It could subsequently inform future music therapy practice.

\section{Statement of Purpose}

The purpose of this research is to gain an understanding of the perceptions of adult individuals on their experiences of an improvised receptive music therapy raga intervention. It is hoped that this information may provide greater insight into how raga might be knowledgeably incorporated into music therapy contexts.

\section{Primary Research Question}

The primary research question established for this study was: How do participants describe their experiences of an improvised receptive music therapy raga intervention (Raga Desh) that takes place in a group context? The primary research question resulted in five overarching themes that emerged as the process unfolded. These overarching themes were then used to establish four subsidiary research questions. These subsidiary research questions were:

- What is the nature of the pre-contextual thought processes inherent to the participants' experiences?

- How do participants describe the musical guidance or the "cognitive holding space" expressed in the receptive raga intervention? 
- What are the participants' experiences of emotional/physiological changes throughout the musical movement?

- What are the participants' perceptions of the duration of the intervention?

\section{Assumptions}

As the researcher, I had some assumptions that are identified here. I assumed that most participants perceive receptive music therapy interventions that incorporate raga as positive or meaningful experiences. I assumed that raga could have cross-cultural clinical relevance. I also assumed that music therapists would be open to using raga in their work even if unfamiliar with the genre.

\section{Key Terms}

The following key terms were defined to ensure coherence and consistency throughout the study.

Raga. Raga has many definitions in the literature and I have incorporated these as well as my own experiences as a student of this tradition to inform the definition established for the purposes of this thesis research. For the purpose of this research, raga is defined as a series of tones with specific melodic motifs (Menuhin \& Davis, 1979) that, when played in a primarily improvised manner, expresses a particular emotion (Moreno, 1988) and creates a specified aesthetic experience. These improvisations adhere to the known patterns of traditional Hindustani or Carnatic music taught to the performer by a recognized Guru or established educational institution of Classical Indian Music (U. Neumann, personal communication, April 2, 2002). As noted earlier, the particular raga used in this research was Raga Desh. Refer to Musical Experience Delimitations for details on this raga. The raga movement performed was the alap. Refer to Raga as Improvisation for details of this movement.

Receptive music experience. A receptive music experience is defined as one where the participants are listeners who respond to the music silently, through personal reflection (Bruscia, 2014).

\section{Chapter Outline}

In Chapter 2, the literature review further defines raga in addition to its current use in music therapy settings. The multi-cultural potential of raga is addressed as well as its potential applications in mainstream music therapy settings. Chapter 3 outlines the selected research methodology: Interpretative Phenomenological Analysis. Chapter 4 presents the research findings, which feature narrative accounts of the participants' experiences. This is followed by 
the discussion in Chapter 5, which addresses the subsidiary questions that emerged from the coding process. In addition, suggestions for further research as well as clinical implications of the receptive raga experience are recommended. 


\section{Chapter 2: Literature Review}

Indian raga has been largely an oral tradition where the Guru or teacher, passes the information to the student or Shishya, and this might explain the little existing literature to date on the use of raga in healing. The composers of the ragas are almost always unknown (Sharma $\&$ Chakroborty, 2017). It is believed that these composers had attained a state of ego-lessness as they chose to attribute their contributions to the place (region) where the music was composed rather than attaching their personal name to it (Sharma \& Chakroborty, 2017). This chapter reviews the existing literature pertaining to the essence of raga. This includes the research within multiple disciplines and the current music therapy literature, as well as the perspectives of musical scholars and performers of both Western and Indian classical music. Within the Defining and Contextualizing Raga section, the traditional emphasis of the listener's experience is examined. Next, the traditional use of raga in India for healing practices as well as its use in music therapy settings is detailed. Similarly, cross-cultural use of classical Indian Raga in music therapy is explored as well as emerging research on how its practice could be incorporated into mainstream music therapy settings.

\section{Defining and Contextualizing Raga}

Raga as emotion. "Raga expresses a mystic significance of life" (Sundar, 2005, p. 1). Although raga has been studied and deconstructed over the centuries, there is still no universal understanding as to what raga is. Translated from Sanskrit, raga means "emotion" and is viewed as particular melodic shapes that produce an experience of pleasing coloring of the mind (Dona, 2012). The melodic shapes or sequences are not set, allowing for it to be fully realized through improvisation (Dona, 2012). These melodic shapes are recognizable yet fluid in so much as the nature of recording the motifs in the raga does not lend itself well to transcription. The ornamentation and phrases, as well as beginnings and endings of particular motifs all blend together in a form of Gestalt (Rao et al., 2014). It may be clearer to understand what raga is not, rather than what it is. Raga is not simply a mode; although, the concept of mode has not been fully agreed upon either (Bowling, 2013). Although the raga shares the basic structure of a Greek or church mode, there are unique differences (Powers, 1958). Within each raga's modal structure, there are intricate accidentals that are specifically placed as a means of creating slight and subtle tension; for example, the flattened $7^{\text {th }}$ in Raga Desh is approached purposefully and in a particular way in this Raga, and for a specific amount of time to evoke a sense of profundity in the listener 
(Kaufmann, 1965; Khan, 2005, track 1). Thus, many different ragas may be played over the same mode. Ragas also do not contain the element of Western harmony or counterpoint. There is primarily one melodic voice that plays over a consistent tonic chord. This "tonic drone" permeates throughout the whole composition and is often played by an accompanying stringed instrument called the tampura. It creates a musical environment that allows for different melodic possibilities to evolve (Powers, 1958; Dona, 2012).

Raga as improvisation. The movement that most purely encompasses raga is the Alap in North Indian (Hindustani) music, or the Alapana in South Indian (Carnatic) music (Powers, 1958; Viswanathan, 1974; Ruckert, Khan, \& Khan, 2009). This movement could be compared to an improvised exposition or cadenza in Western classical systems, where the player develops the theme of the melody. The movement is played without the accompaniment of the tabla (Indian drum) and can accompany other movements or serve as a stand-alone movement in itself. Within this one movement is a division of three other movements, each with greater rhythmic intensity; these are optional depending on the mood of the player and listeners. A musician needs a great amount of expertise on the instrument to properly create the desired mood of the particular raga. It is traditionally the final movement that the Guru introduces to the student or Shishya when he or she has an advanced understanding of raga (S. Parvez Khan, personal communication, May 1, 2012). This form will vary in length, as the musician will expand motifs through manipulation of tempo, ornamentation and elaboration (Viswanathan, 1977). The movement could be anywhere from one minute, to several hours depending on the mood of the listener and the intention of the performer (Dona, 2012). Alap movements in ragas have been analyzed with some commonalities found in the development of motifs (Viswanathan, 1977). These motifs follow a particular pattern of starting in the lower range and moving up to the upper octaves and descending back down to the lower range upon completion (Viswanathan, 1977). This particular contour is fundamental to the correct execution of the raga, and one can speculate as to how it affects the listener's experience.

\section{Raga as Experience}

Bhava (emotional expression). Bhava, is the emotional expression of the raga (Clayton, 2001). When the raga is correctly executed, it will create a mood or energy that permeates throughout the environment. 
Rasa (experiential effect). Rasa is the experiential effect of raga, be it energy, revitalization, or aesthetic appeal that the bhava elicits upon the listener (Clayton, 2001; Dona, 2012). Sundar (2005), a researcher of raga in clinical settings in India, describes the traditional forms of Indian music as follows:

The vast repertoire of kirtans, kritis and bhajans with a devotional touch, the psychological value of the tonal configuration of different ragas and the voice when presented exclusively rather than casually in a concert atmosphere to the clients delivered by voice exudes a kind of naturalness and magnificence, which reaches the soul more effectively than the touch, glance or even movement. (p. 1)

The "state of mind" cannot simply be defined by constructs such as timbre, scale and meter, but can only truly be defined through the human experience (Clayton, 2001). Music therapist and researcher, Ruud (2013), also identifies the importance of how the listener receives the music. Rather than focus on how music affects basic brain function, it is more important to understand how the musical meanings are processed at the cortical level (Ruud, 2013). Thus, in both music therapy and the perception of raga, there appears to be a philosophical intersection in that the listener's musical experience is more than the sum of its parts. It is not simply a series of tones that affect a series of neurons in one's brain, but rather it involves more complex processes in the listener's perceptual experience. From this, one can see how further research into the rich experiential effects of raga (as opposed to its biological, or physical effects) may be needed.

\section{Raga as Sound Vibration}

Sound is fundamental to the healing process in Vedic tradition and early Indian writing; it is believed that all things in the universe are made of vibrations (Cook \& Cook, 1997; Sundar 2007). At the same time, the concept of sound as a healing process is not alien to Western ontology, from the idea of "cosmic vibrations" of the New Wave theorists, to regular vibrations that are produced through sound waves (Ruud, 2013). If one were to look at the sitar, an East Indian plucked string instrument that very loosely resembles a Banjo, one can see a series of strings underneath the instrument that are particularly tuned to each raga prior to each performance and that resonate when the other strings are plucked. These resonating strings can also be seen in other Indian classical instruments. One music therapist conducted research and fieldwork with a healer of sacred music therapy in an Indian village. At the time, the healer 
indicated that the music creates a particular state of vibration that allows healing (Cook \& Cook, 1997).

Kaufmann (1965) also illustrates how Raga hypnotically brings forth the desired reverberation in the listener. Indian music therapist Sundar (2007) links this reverberation to the Vedic tradition or the early Indian writings. Ragas and their sonic qualities are believed to be connected to healing various conditions, both mental and physical. She describes Nada Yoga as an ancient form of yoga related to sound, where focused listening to the inner sound within one's body is encouraged to facilitate healing (Sundar, 2007).

\section{Raga in Music Therapy}

When raga is used in traditional healing in India, the person listening to raga does not participate in the playing process; it is primarily a receptive experience (Lee \& Houde, 2011). Thus, it may be more realistic to have Hindustani or Carnatic classically trained musicians work with a music therapist in creating the receptive experience in practice. Another option would be the music therapist using high quality recordings of preselected ragas in sessions. The following two approaches have been researched and found to be effective with Indian populations. In one Indian study with adolescents, live receptive raga music therapy was shown to be effective in boosting the participants' levels of self-esteem over the control group who had not received treatment over a 15-day period (Sharma, \& Jagdev, 2012). However, results were not generalizable to populations outside the Punjabi region of India (Sharma, \& Jagdev, 2012). As noted earlier, a study in a psychiatric hospital in India showed that live receptive raga was used in music therapy to alleviate states of depression and improve patient well-being (Deshmukhet et al, 2009). This study found that participants who listened to raga, scored higher, or exhibited lower states of depression, than the control group of patients receiving psychotropic treatment (Deshmukhet et al, 2009). Furthermore, the group that listened to Raga maintained this mood state for a longer period than did the control group (Deshmukhet et al, 2009). In a case study with one North Indian participant who was experiencing depression during pregnancy, it was found that receptive music therapy raga interventions using recordings of sitar and flute decreased her symptoms of depression over a 20 session period. The raga recordings were used according to the particular times of that they were traditionally played and that corresponded with her emotional and physiological needs as per an ayurvedic tridosha assessment (Sundar, Durai, Parmar, 2016). 


\section{Raga Through a Multicultural Lens}

Raga as a universal language. Nada Yoga, an Indian healing practice that incorporates raga through voice, views music as a universal presence (Sundar, 2005). Furthermore, it has been argued that music can transcend cultural barriers, although not always the symbolic context associated with the musical idiom (Brown, 2002). Subsequently, it has been found in crosscultural studies, that both experienced and non-experienced raga listeners had similar perceptions of the emotional intent of particular South Indian and Western scales for various emotions, including joy and sadness (Balkwill \& Thompson, 1999; Sundararajan, Han, \& Purves, 2012). Moreover, it was found that variations in spoken tonal inflection to express emotions in both English and Tamil were similar and reflected the tonal characteristics in both ragas and Western music. Consequently, results demonstrated a relationship between emotional states, tonal characteristics in cross-cultural populations (Bowling, Sundararajan, Han \& Purves, 2012). Furthermore, larger tonal intervals in both music styles demonstrated a state of happiness, whereas smaller intervals within the mode demonstrated more subdued emotions (Bowling 2013, Bowling, Sundararajan, Han \& Purves, 2012). These studies support the hypothesis that there are

psychological, physical and emotional responses common to all individuals, regardless of culture, in response to hearing particular modes (Balkwill \& Thompson, 1999). It further supports the idea that, on some level, music may evoke a pure emotional feeling as humans all share some similar cognitive and emotional functions (Brown, 2002).

\section{Raga and the Importance of Context}

From a music therapy perspective, music is not simply prescriptive in terms of eliciting an individual's emotions; memories and context are also involved (Stige, 2007; Ruud, 2013, Sundar, 2016). At the same time, music therapist and scholar Stige (2007), asserts that assuming that music, when not part of an individual's culture, would have no meaning, is equally insensitive. He sees the importance of understanding each person by considering the intertwining individual and contextual factors that make them who they are. Cultural meaning for an individual can be complex; one might connect to particular music in different ways and for different reasons that are unpredictable (Stige, 2007). For example, clients with no previous knowledge of a genre may benefit from the lack of pre-associations elicited in the music; at the same time, clients may find the unfamiliarity of the music to be displeasing (Moreno, 1988). Similarly, clients originally from India, are from an area of various generational differences, ethnicity, and religion. This means 
that she or he will have different connections to this music. It is not expected that a client who is Indian and familiar with raga improvisation will want to hear this music (Lee \& Houde, 2011). Thus, using ragas to help clients could be beneficial as long as the individual's preferences as well as multi-cultural sensitivity are taken into consideration. While raga may have cross-cultural effects as previously illustrated, one cannot assume that there is a musical style for all individuals.

\section{Potential Applications of Raga in Cross-Cultural Settings}

Music therapist and scholar Brown (2002) further notes that raga could be beneficial when used in relaxation and visualization activities within music therapy practice. However, in cross-cultural settings, it may be logistically difficult to incorporate live musicians in receptive experiences. Furthermore, music therapists with familiarity with the genre may not feel comfortable playing in the idiom (M. McGrath, personal communication, March 1, 2016). As previously stated, Indian music therapists and clinicians have identified the potential for the use of raga in receptive experiences such as guided imagery sessions (Sairam, 2006). Thus, the use of recorded music may be a more realistic alternative; although it would lack the interactive and intuitive contributions of a live musician. Australian and European based music therapists and researchers Grocke and Wigram (2007) speak to the use of recorded sitar in meditative receptive experiences in settings outside of India.

The Western classical violinist Menuhin (Menuhin \& Davis, 1979), who studied raga extensively, finds different aesthetic purpose in raga than Western classical music. While Western classical music favours sharp contrasts in mood, to take the client on an emotional odyssey, raga may stay within one mode for long periods of time to create an emotional state (Menuhin \& Davis, 1979). Music therapy has a tradition of using Western classical music as the preferred genre for visual and relaxation inductions. For example, the Bonny Method of Guided Imagery and Music (GIM), currently a very well-known method of receptive music therapy, traditionally uses classical Western music (Grocke \& Wigram, 2007).

One of the primary techniques of GIM is having the client achieve through prepared listening selections a state of transpersonal awareness; the client gains further understanding of herself or himself, transcends ego, and finds connection to a collective state of consciousness (Bonny 1999; Bruscia, 2015). In similar fashion, Indian classical musicians maintain that raga traditionally allows individuals to enter deep introspective states, a mindset that provides them a 
forum to connect with the greater universe (Lee \& Houde, 2011). There is some interest in and research exploring the inclusion of additional music programming to GIM (Meadows, 2010); this includes Ng's (2017) research in GIM using Chinese classical music; however, with Chinese and Hong Kong Chinese populations. The inclusion of raga could hold potential, depending on the goals of the intervention.

Sairam (2006), a medical doctor who works with raga and healing in India, notes "While the slow-paced rhythms and tempos slow down the mental pace, leading towards calmness, they are also found to be capable of diverting the thought processes in mind, thus enhancing relaxation" (Sairam, 2006, p. 881). Furthermore, there is a lack of literature as to how live raga improvisational receptive experiences have been used in North American clinical settings at present. As previously mentioned, traditional improvised Alap movements follow a particular contour as part of the listening experience (Viswanathan, 1977). As traditional forms of GIM pay attention to a specific contour (Meadows, 2010) that the music follows, much could be learned through the interdisciplinary synthesis of both approaches.

\section{Music Therapist Education in Raga}

"Music therapists must take the high road and research and learn what will work for their clients" (Brown, 2002, p. 1). With the diverse needs of clients in a constantly growing multicultural climate, it seems fitting that music therapists develop an understanding of raga. What brings additional complication is the fact that raga is largely an oral tradition. When this music is notated, it is written in a basic solfege, where the intricate ornamentation is considered already known and internalized. Therefore, it is not always possible to attain knowledge from previous literature. Instead, one must go to the individual to attain the knowledge directly. McGrath, a Canadian music therapist, has contributed to the work of Lee and Houde (2011), who have compiled an introductory instructional chapter on a selected group of ragas, their modal origins, and how to use these ragas with multicultural sensitivity when working with specific clients of South Asian descent. Further research, particularly in receptive experiences of improvised raga, with cross-cultural populations, is warranted in the hopes of sensitively incorporating it into mainstream music therapy practice.

\section{Summary}

Defining raga has and continues to be a difficult endeavour. Loosely translated, raga means emotion. Rasa is the experience or aesthetic created by the raga (Dona, 2012), while bhava 
is the emotional content of the work (Kaufmann, 1965,). The movement that most purely encompasses raga is the improvised movement known as Alap or Alapana (Powers, 1958; Viswanathan, 1977; Ruckert, Khan \& Khan, 2009). Traditionally, ragas have been thought to have mental and physical healing properties. There has been evidence that raga has similar emotional effects on individuals regardless of cultural background or knowledge of the genre (Bowling, Sundararajan, Han, \& Purves, 2012). Studies in Indian psychiatric hospitals have found that raga has boosted levels of self-esteem and reduced states of depression. Raga has been recommended cross-culturally in receptive experiences in visualization and meditation. The slower movements of raga have been known in Indian clinical settings to slow down thought processes, facilitating relaxation inductions. Although raga, like any form of music, should be clinically integrated into Western and Eastern cultures with a multi-cultural sensitivity (Brown, 2002), cross-cultural use of classical Indian raga in music therapy has a great deal of potential. Lee and Houde (2011) have compiled an introductory instructional chapter on a select group of ragas as well as their modal origins for music therapists. However, to date there is a lack of qualitative research describing an individual's unique impressions of a receptive raga music therapy experience. 


\section{Chapter 3: Methodology}

\section{Design}

This qualitative research study used Interpretative Phenomenological Analysis (IPA) to analyse and describe participants' experiences of an improvised receptive raga music therapy intervention (Smith, 1996). Phenomenological studies value personal perspective and human subjectivity as a way of truly understanding and interpreting experience (Lester, 1999). Scholars and performers agree that the essence of raga can only be defined through human experience. Furthermore, based on my experience in the field, the nature of individual responses may be varied and complex. To account for this complexity, IPA is an appropriate methodology choice as it allows for a detailed understanding of how participants make sense of their experience (Smith, Larkin \& Flowers, 2009). Furthermore, IPA departs from traditional phenomenological investigation, as within this approach, a "double hermeneutic" (Smith et al., 2009, p. 9) is present. Here, participants attempt to construct meaning from their experience while the researcher attempts to understand the participants' construction of their experience (Smith \& Osborn, 2008; Smith et al., 2009). Consequently, IPA could be viewed as equally phenomenological and social constructionist. IPA's social constructionist commitment, where reality is constructed through the interplay of two individuals' social and contextual worldviews (Nuun, 2009), is also aligned with multicultural perspectives in therapy (Monk, Winslade, Sinclair, 2008). As previously mentioned, there is a need for maintaining a multicultural awareness when clinically integrating raga into music therapy practice. As in social constructionism, the multicultural paradigm appreciates that multiple worldviews, context, discourse and power dynamics affect an individual's recounting of an experience (Monk et al., 2008). It is fitting that the understanding of raga in a research setting employs a complimentary method of inquiry.

\section{Delimitations}

Participant delimitations. The number of participants in this study was delimited to three. In IPA, three is the suggested number of participants in a magisteriate level study: this number allows for rich detail in each case analysis while also being a sufficient number to account for group themes (Smith et al., 2009). Participants were to have no previous or current mental health issues and were not to be taking any anti-anxiety or mood altering medication. They were to be 18 years of age or over. These participants were not to be players or active 
listeners of raga; this was designed to avoid any particular pre-associations or biases that active listeners might have for this music. Participants were not to be personal acquaintances, or within my social network; this was designed to control for the effect of familiarity on accuracy and truthfulness of participant responses (response bias). Participants were also to be fluent in English; this was designed to ensure effective analysis of the semi-structured interviews, which rely heavily on communication, metaphor, and interpretation.

Musical experience delimitations. Participants were presented with only one receptive raga music therapy experience, and that was in a group context upon which to base their perspectives. Given the nature of qualitative research, numerous participants and different ragas would have detracted from the rich output and detailed analysis required for each participant's experience. The particular raga played was delimited to Raga Desh, as it is a raga that I have previously used in clinical work and is one that appeared to resonate with clients during verbal processing in the field. The raga is known both in North and South Indian music. The word Desh has a connotation of country, and reflects a multi-cultural sentiment within India. The raga has been traditionally described to evoke emotions ranging from romance to personal longing (U. Neumann, personal communication, May 18, 2008). It has tonal elements of the major scale, the flattened seventh of the mixolydian scale, with set rules for ascending and descending. This allowed for rich and less characteristic improvisational possibilities while still having an element of familiarity. Time limitations made it impossible to explore other ragas within the experience. The movement was delimited to the alap movement; as previously stated, it has been known to most purely express the spirit of raga (Powers, 1958; Viswanathan, 1974; Ruckert, Khan, \& Khan, 2009).

\section{Recruitment Procedures}

Upon receipt of ethics approval from the Concordia University Human Research Ethics Committee (UHREC), 10 recruitment posters (see Appendix A) were displayed at specific centers affiliated with Art Hive, a locally-based community arts organization. An additional 100 posters were displayed in multiple academic departments (after approval) throughout McGill and Concordia university campuses in Montreal, Canada.

Five individuals who met the inclusion criteria were selected on a first come first served basis. Five individuals, as opposed to the recommended three, were selected in the event that some participants did not attend on the day of the experience. I met with the selected participants 
to explain the study, to sign the informed consent form and to give the time and location for the intervention. This form included details on risks and benefits, data collection procedures, withdrawal and confidentiality (see Appendix B). . On the day of the experience, the first three participants to sign up for interview times were selected to have their interview data analyzed and therefore be part of the research.

\section{Participants}

Participants were three adults who were volunteers from the general population, ages ranging from 20 to 50 years old (see Table 1 below); pseudonyms have been used to protect participant anonymity. The first two participants self-identified as males and the last participant as female. A variety of identified ethnic, cultural and linguistic backgrounds were identified in this sample. Two participants identified as professionals and one as a student. All participants were non-active listeners of raga and expressed various tastes in music ranging from French songs to Western classical to electronic music.

Table 1: Demographic Information of Study Participants

\begin{tabular}{|c|c|c|c|c|c|c|}
\hline $\begin{array}{l}\text { Participant } \\
\text { Pseudonym }\end{array}$ & Age & $\begin{array}{c}\text { Self- } \\
\text { identified } \\
\text { gender }\end{array}$ & $\begin{array}{c}\text { Self- } \\
\text { identified } \\
\text { ethnicity }\end{array}$ & $\begin{array}{l}\text { Primary } \\
\text { language }\end{array}$ & $\begin{array}{c}\text { Primary } \\
\text { occupation }\end{array}$ & $\begin{array}{c}\text { Preferred } \\
\text { musical } \\
\text { style(s) }\end{array}$ \\
\hline Andrew & 35 & Male & $\begin{array}{c}\text { White, } \\
\text { South } \\
\text { American }\end{array}$ & English & Therapist & $\begin{array}{c}\text { Experimental, } \\
\text { ambient }\end{array}$ \\
\hline Pierre & 50 & Male & Caucasian & $\begin{array}{c}\text { French } \\
\text { (with } \\
\text { English } \\
\text { proficiency) }\end{array}$ & $\begin{array}{c}\text { Computers, } \\
\text { Self- } \\
\text { Employed }\end{array}$ & $\begin{array}{c}\text { Classical, } \\
\text { French songs }\end{array}$ \\
\hline Zara & 20 & Female & $\begin{array}{l}\text { African } \\
\text { Canadian }\end{array}$ & English & Student & $\begin{array}{l}\text { Electronic, jazz, } \\
\text { classical, rock }\end{array}$ \\
\hline
\end{tabular}

\section{Materials}

A digital audio recorder was used for the interview. For the musical experience, a classical Indian sitar designed and strung according to the specifications of the Etawah, Gharana School was used. The sitar was mildly amplified using a contact microphone, a Yamaha MG-06X 
mixing console, and a Bose F1-812 multiple array loudspeakers. Cushions, mats, and chairs were made available for participants to sit on.

\section{Data Collection Procedures}

The receptive experience took place in a soundproof room at Concordia University and was facilitated by me. The interviews took place in an adjacent room. Another graduate student research volunteer was present to assist with participants' arrival, transfer to the interview room, and departure, and to distribute the demographic questionnaire (see Appendix C).

Participants were first brought into the room to sign up for the post-experience interview that immediately followed the experience. They were then invited to sit comfortably on cushions, a chair, or the floor. Participants were welcomed to the experience by me. The different phases of the experience were briefly explained, and participants were provided with the approximate duration of each phase. The first phase of the improvised receptive raga intervention consisted of a 3-minute relaxation breathing induction (see Appendix D). This was to enhance participants' focus as customary in music therapy settings. The second phase consisted of a 15minute improvised raga on the sitar in the Alap movement in Raga Desh played by me. The movement included three sub sections: the exposition; the jhala or introduction of a rhythmic ostinato; and the jhor, involving a slight increase in tempo. After the improvised receptive raga music threrapy intervention, participants were invited to the adjacent interview room. While waiting their turn, participants were given a basic demographic information questionnaire to complete.

Semi-structured interviews were conducted individually by myself and lasted between 10 to 20 minutes. Through a series of open-ended questions (see Appendix E for Interview Questions), participants were guided to describe their experience, focusing on how they felt emotionally both during and after the intervention. It was communicated beforehand that for the purpose of the study, participants were invited to be as transparent as possible with their answers. This included any negative experiences that they may have had during the process.

In IPA research, both researcher and participant engage in a dialogue where both parties attempt to understand the participant's accounting of her/his experience (Smith et al., 2009). To achieve this, I adapted and reformulated questions based on the participant's answers during the interview process. Other questions emerged depending on client responses. I also took notes during the interview process in order to revisit and highlight particular participant responses at a 
later point in the interview (Smith et al., 2009). To establish transparency as well as to allow for a less intimidating interviewing atmosphere, participants were invited to look at these notes during the interview process.

\section{Data Analysis Procedures}

Recorded interviews for participants were collected and transcribed. Initially, each interview was analysed individually. Before analyzing each of the participants' transcripts, I engaged in a process called bracketing (Smith, Larkin, \& Flowers, 2009). Here, I conducted a free-write, where I wrote down everything that I knew about raga, my own experiences and perceptions of other people's experiences of the music, as well as my own interpretations of the not-yet analyzed transcript. The purpose of this exercise is to acknowledge any inherent biases or preconceptions that may affect the analysis procedure.

After transcription, the recorded interviews were played back at least once while reading the transcripts. The transcripts were then read several times during which I added descriptive comments written on the left margin. These were followed by comments pertaining to the use of language as well as metaphor. Metaphor can allow for a rich understanding of the relational dynamic of music (Clayton, 2001; Kenny, 2006). Finally, more conceptual comments including my interpretation as well as my free-associations of particular words in the transcripts were added to the previous two groups of comments. This coding process is unique to IPA (Smith, Larkin \& Flowers, 2009).

In a process called axial coding, these notes were put into themes or concise phrases on the right hand column of each transcript. Themes were then prioritized and clustered based on potential relationship and given super-ordinate theme titles through a process called abstraction,

while some themes were developed into super-ordinate themes as they linked groups together in a process called subsumption (Smith et al., 2009). These themes were subsequently crossreferenced with the raw data (direct quotes in the transcription) as per the selective coding process. Next, I took emerging super-ordinate themes and subsidiary themes from all transcripts and created an overarching table of themes for the group, each with their own subordinate themes.

The themes were next turned into three client narratives highlighting the group thematic experiences of the phenomenon while adhering to their own personal accounts. Participants were also given the opportunity to review the story via email, and to edit, elaborate, and clarify as 
needed to thereby ensure the authenticity of each participant's experience. My supervisor offered guidance to ensure themes were well organized and emerging from the gathered data. 


\section{Chapter 4: Results}

As a result of the IPA of the three participants' experience of the raga music therapy intervention, five overarching themes emerged from the data. The themes were as follows: (a) initial awareness of sensory stimulation/environment; (b) pre-contextual thought processes as inherent to the experience; (c) raga as trusted guide; the development of a "cognitive holding space" through music; (d) emotional and physiological changes throughout the musical movement; and (e) preferred duration of experience. The following overarching themes as well as their subsidiary themes are explored in the following section through three narrative accounts representative of each participant.

\section{Table 2: Overarching Themes and Related Subsidiary Themes}

\begin{tabular}{|c|c|}
\hline Overarching Themes & Subsidiary Themes \\
\hline \multirow[t]{2}{*}{$\begin{array}{l}\text { Initial awareness of sensory } \\
\text { stimulation/environment }\end{array}$} & $\begin{array}{l}\text { "Here and now; presence of the room, people around me, } \\
\text { smells" }\end{array}$ \\
\hline & Physical Self \\
\hline \multirow{2}{*}{$\begin{array}{l}\text { Pre-contextual thought processes as inherent to } \\
\text { the experience }\end{array}$} & Presence of past and future thoughts "real thoughts" \\
\hline & Initial pre-associations with music of sitar/genre \\
\hline \multirow{5}{*}{$\begin{array}{l}\text { Raga as trusted guide; the development of a } \\
\text { "cognitive holding space" through music }\end{array}$} & Musical safety while being allowed to mentally explore \\
\hline & Support in experience \\
\hline & Fluidity of the music and thought \\
\hline & Increase in musical intensity facilitated cognitive experience \\
\hline & Music distancing oneself from present/physical reality \\
\hline \multirow[t]{3}{*}{ Emotional and physiological changes } & Comparisons to a sleep like state \\
\hline & Physical sensation \\
\hline & Emotional changes \\
\hline Preferred duration of experience & $\mathrm{N} / \mathrm{A}$ \\
\hline
\end{tabular}


The essence of the overarching themes is more fully explained within the first narrative account. Accounts consist of verbatim extracts from the source material (interview transcripts) as well as my own interpretation. In an attempt to address the idiographic nature of the methodology (Smith, Larkin \& Flowers, 2009), any divergence and convergence within the participants' experiences are explored within this recounting.

\section{Andrew's Experience}

Initial awareness of sensory stimulation/ environment. The first overarching theme illustrates the awareness that the group members had of the environment in the initial stages of the experience. This included their awareness of the room, the other participants, and the sounds in the environment. The following subsidiary theme emerged from Andrew's own words.

“Here and now; presence of the room, people around me, smells." In the first subsidiary theme, Andrew describes his experience as moving or "journeying" between different phases. In the beginning of the interview, he brings attention to his sensory and contextual surroundings, which he describes as "here and now."

I had an experience of "here and now". Presence of the room, people around me, smells... (Andrew)

His use of the term "here and now" gives a sense of a heightened awareness of his immediate physical and sensory surroundings as opposed to the more mentally internal stages later in his journey.

Physical self. Andrew also expresses awareness of his physical self.

I'm familiar with Vipassana meditation and getting into the body and scanning various portions of my body, but in this case I stopped that because that's not what I was instructed to do. (Andrew)

Here again, he shows a physical awareness. He associates the experience to Vipassana, and feels the need to check in with his physical presence but stops himself. Andrew appears to have a meta-cognitive awareness of his own default thought processes as demonstrated in his mental dialogue.

Pre/ post-contextual thought processes as inherent to the experience. The following overarching theme illustrates how future thoughts as well as both immediate past, and earlier associations with the music have influenced Andrew's experience. 


\section{Presence of past and future thoughts "real thoughts."}

Yeah, I think I went through various states [pause] It wasn't like phase 1, phase 2, phase

3. It was more like... present space, then I moved into real thoughts of what I might have to do after this, while still being present. (Andrew)

Andrew describes how he appears to oscillate in and out of different states of awareness in a non-linear fashion. In the above excerpt, he describes a new phase of awareness: past and future thoughts. He describes these thoughts as his "real thoughts" as if to describe a phase that he is most familiar with, a type of reality that he oscillates in an out of while still having the awareness of the present during the experience.

Initial pre-associations with music of sitar/genre. In this theme, Andrew describes some of the past thoughts that came to him during the music in the form of pre-associations.

Interviewer: Could you explore anything else that it [the music] reminded you of? Andrew: $\quad$ Oh yeah, interesting ... yeah it reminded me of some music that contained a sitar that I had heard when I was younger so there was kind of a nostalgic element to it.

Here, one can see that the music evoked a sense of nostalgia, an aspect of the listening experience that might also be shared by active listeners. He continues,

but I think I just, yeah [pause]. I guess it wasn't necessarily a judgement, it was more just a "Oh I was expecting something different from the instrument at first" (...) like a louder more pronounced fullness and it was actually quite simplified, and with time it transformed and became fuller and fuller. (Andrew)

The previous is an illustration of how Andrew's preconception of sitar music was inherent to his perception of the experience. Although he is not an active listener of raga, he still had expectations as to what the music might be like. His preconceptions are challenged as evident in his account.

\section{Raga as trusted guide; the development of a "cognitive holding space" through music.}

Within the participants' experiences of the Raga performance, the thematic elements of safety, support, fluidity, increase in musical intensity, and the music distancing oneself from reality emerge from the data. Together they create the overarching theme of the music as guide, a phenomenon where a cognitive holding space has been created. This is further illustrated in Andrew's account. 
Musical safety while being allowed to mentally explore. The sense of familiarity that Andrew previously mentions in the last theme further builds a sense of safety, which is explored in this theme. In this passage, one can see how Andrew takes comfort in the simplicity of the musical exposition.

Yeah, it sounded almost like folk music at first. Like a basic structure I could understand. Then it started to become more complicated, so... I think at first it was a simple melody that was stripped down and I was surprised by its simplicity. I recall... trying to bring my ear towards it to focus on it and then it started to fill the space. I think it kind of [pause] it took care of me in that sense as it started to fill the room. I could yield into its, [pause] development-progressively. (Andrew)

He reflects that this music developed gradually and that there was a nurturing element to it. Andrew's use of pauses in his statement of 'yielding into its development progressively' is almost analogous to how he experienced the movement, in a slow and gradual manner.

The theme of safety and trust is again explored in a later passage, where he recounts that his ability to 'yield' facilitates his journeying.

I was not trying to elicit it, it just happened. I was surprised by this, kind of like "Oh, look where I'm at." So that was the official kind of experience of my journeying. It's like "Oh, I think I'm going to yield into it and be within this...", yeah it was immersive. (Andrew) In the above statement, Andrew is talking about a phase in his journey that he gradually entered; it is a moment where he finds himself floating. His journeying appears effortless, as he does not initially realize that he got there. Again, the idea of "being with this" gives the impression of trust and safety as the music guides him. He did not need to push or be pushed in his experience; he was willingly taken there.

\section{Support in experience.}

... there was anchoring within the linearity of knowing that it was only going to be 15 minutes. This allowed for an experience of groundedness, but then again, it also allowed me to kind of float and be in a state. So it felt safe, I would say, there was so much safety in it that I allowed myself to journey somewhere. So I think "anchor" would be a term here. [pause] “Anchor”, yes, being able to float. (Andrew) 
Here, Andrew introduces the feeling of 'groundedness' that he attributes partly to the safety of knowing the duration of the experience. 'Anchor' is a rich metaphor for the feeling of support that he had in the experience. To expand on his analogy, he could stray or 'float' as far or wherever he wanted, yet his boat was still connected to a temporal rope that he could follow, allowing him a safe return home.

Fluidity of the music and thought. In the following theme, Andrew elaborates on his feeling of floating in an imaging experience.

I saw some floating imagery, I was floating over trees...Aerial view, and ... then there was a state of kind of seeing the music. Seeing [pause] I remember kind of feeling that there wasn't any linearity to it - although there was, but I couldn't discern one line, it was kind of like two things were happening at once. Then I started to think of the psyche and how it was bringing me through different areas at once. It was sort of keeping me grounded. But there were these higher notes that kinda like... stretched me [laughs]. (Andrew)

As Andrew continues to describe his journey, his description of floating while being grounded becomes a recurrent theme. He describes a lack of linearity where the higher notes continue to stretch his psyche in a malleable or fluid way as he journeys through multiple areas at once. He laughs as if he finds humour in how this description is rich with details, painting a vivid picture, while being abstract in nature. At the same time, it illustrates how Andrew is experiencing a phenomenon that is somewhat novel to him. The music seems to be influencing or accommodating his mental processes.

Increase in musical intensity facilitated cognitive experience. In the next passage, the sonic simplicity and low volume of the initial movement is discussed.

Yeah I think initially... I think I felt it [the music] was actually quiet at first. And I kinda had the sense of wanting it to be louder, cause I could sense the people around me and hear the room creaking and stuff. (Andrew)

In the above excerpt, Andrew further expresses a level of distraction from his surroundings as well as a need for amplitude in the music to detract or refocus his preferred sensory experience. He continues this later in the interview.

I thought it would be more complex and it did get there. But at the beginning it felt stripped down. So I think it progressively worked. Without me analyzing too much, it started off simple and it got me into a rhythm and then it started to get more complex. I 
think my journey felt similar to that, where I began very aware of the room and then slightly more and more I moved internal and inward. (Andrew)

The final movement is the jhor, where the speed and often rhythmic and melodic intensity naturally increases. This experience of movement appears to be a catalyst that guides Andrew along his mental journey. He mentions that this gradual increase in sonic, melodic, and rhythmic intensity "worked" for him as he began with a heightened awareness of his environment and began to move further towards his inner thought processes.

Music distancing oneself from present/physical reality. In the next passage, Andrew describes how he has almost completely left his physical awareness.

Andrew: $\quad$ So I think my body kind of disappeared while remaining grounded in one position. I may have adjusted a couple times on the back of my chair for my spine, as that was the only physical discomfort I had. But outside of that I think everything else really disappeared...

Interviewer: You were on the chair?

Andrew: $\quad$ On the chair, yeah... there was also some stomach awareness at the beginning and I recall feeling it bubble at times, but everything else kind of seemed to fade.

Andrew enters what he had previously described as "inward" awareness; in this state, there is less of a presence of physiological needs, environmental sounds, or the awareness of the people around him. Through his description, one can see what the beginning of this inward phase is like for him. As he states, everything around him disappeared or faded away.

Emotional/ physiological changes. The next overarching theme reflects on the emotional and physiological changes that participants experienced during the experience. Although responses were varied, particular themes that emerged for Andrew will be explored.

Comparisons to a sleep like state. When discussing his general experience, Andrew states "I was kind of on the edge of sleep at one point." This state between sleep and wakefulness precludes his entry into the "internal world." One might wonder whether this sleep-like state was a result of everything else fading around him, which allowed for a deeply focused mental state, or if his body was simply tired and he was becoming aware of it in the moment.

Physical sensation. Andrew continues later in this passage to describe a physical sensation during his imaging. 
No, more of like a summer mountainous space... so it wasn't cold, it was warm. (Andrew)

It appears that Andrew had a sense of warmth at this point as he journeyed through his experience. The sensation does not appear to be vivid through the gradual manner in which he expresses "so it wasn't cold, it was warm." It appears to be a reflection after the fact, more of an accompaniment to what is happening for him in his visual experience.

Emotional changes. Andrew describes a feeling of calm at the end of the experience.

So the sensation was, there wasn't any anxiety or fear, it was very calming... and I guess it was kind of birdlike so... if I were to be embodied in that I would have been a bird. (Andrew)

His description of being a bird as an expression of calm gives the impression of releasing a burden. The bird is a rich metaphor for a sense of freedom and weightlessness from the outward world as he hovers above his reality.

\section{Preferred duration of experience.}

There was one point I saw some imagery come up, that I couldn't categorize as present, future tense, or past tense, it was just kind of dream like. (Andrew)

In Andrew's account of his experience, he describes a state of timelessness. He is not in the present, the future, nor in the past, but in the moment. Although this timeless mental state of not going in the past, future nor present seems uncertain, he later describes a feeling of safety as he navigates this state of mind.

I think there was an overall structure to it. We started with a breathing exercise and knowing the duration of it. You know, establishing 10-15 minutes, gave me a sense of like, okay I can give in to that. (Andrew)

Andrew hesitates to find his words prior to constructing the idea of giving in to the music. One can sense a feeling of comfort in his timelessness experience.

\section{Pierre's Experience}

Pierre's account of the experience was also analyzed through the same themes and subthemes with specific attention given to his own unique experience.

Initial awareness of sensory stimulation and environment.

“Here and now;" presence of the room people around me smells...”

Interviewer: So - what was your general experience of the musical performance? 
Pierre: I had a little trouble to let myself be engulfed by the music. I must say that I was a little bothered by the creaking noises in the room-the creaking noises there. The beginning really bothered me.

In the first sub theme, Pierre mentions his distraction and awareness of the room around him. Like Andrew, he appears to have a heightened awareness of his surroundings, particularly the creaking of the room.

\section{Physical Self.}

In the beginning I was a little troubled not to fidget and not to move there, but at the end I was more into it. (Pierre)

Here, he describes his initial discomfort; he demonstrates an awareness of his body through his description of uncertainty as to how he should be sitting.

\section{Pre/post-contextual thought processes as inherent to the experience.}

Presence of past and future thoughts. In Pierre's recounting of his experience, he describes his personal context.

At the beginning of the experience when I came in room... I was a bit troubled with personal problems. (Pierre)

One can see that personal context was inherent to his experience as it was something personally relevant for him to mention. His immediate past experience was something that he had brought with him when he entered the room. He previously mentioned difficulty that he had in focusing on the performance. One wonders if the "background noise" that Pierre did not want to hear was as much his ruminating thoughts as they were the sounds in the room.

Initial pre-associations with music of sitar/genre. Pierre describes his pre-associations of the sitar and this music brought back memories for him.

In the previous statement, Pierre describes how his associations with the music are linked to his experience of watching movies where this, or similar style of music is used to depict India. He continues with some of the further associations he makes with this music.

Of course you associate also with the Beatles. Back in the 60's, the hippie times there, that type of music. (Pierre)

Here, Pierre associates the style of music to a particular era and links a counter cultural movement that he feels has embraced or is strongly affiliated with this music for him. Pierre associates the music to Western classical music. It is less about the distinct sound or past 
experiences that elicit the experience but more about the essence of the music. The music allows a sense of familiarity and safety. This is explored in the next overarching theme and in the following passage from Pierre's account.

\section{Raga as trusted guide; the development of a "cognitive holding space" through} music.

\section{Musical safety while being allowed to mentally explore.}

But it was a very soothing type of music, I listen to a lot of classical music and it's a little bit the same, maybe not musically there, but it's non-vocal... you don't have to listen intently, you just let yourselffloat away with the music... (Pierre)

As previously mentioned, in this example, the familiarity in the music is less about the sound or pre- associations, but more about the essence of the music. Pierre describes what one could perceive as a holding space that the music is creating for him. The music is not attempting to draw upon his immediate attention. It appears to create an atmosphere for him to "float away" in his thought processes. The idea of floating was also apparent in Andrew's account and seems to be a recurrent theme. One can envision the music to be like water. It is fluid, constantly changing, yet buoyant and allowing for support.

Support in musical experience. The theme of support explicitly emerges within Pierre's account. In his statement, he explains how the raga performance facilitates his desired state of mind.

The music is a support for your feeling better... (Pierre)

One can see the emergence of the holding space that allows Pierre the ability to reach his desired emotional state. Later in the interview, when talking about the music, he constructs the following theme: "Feeling strong by something soft." One can again see that something fluid, soft, unassuming and buoyant is lifting him or empowering him.

Fluidity of the music and thoughts. Pierre further elaborates on the fluid and water like nature of the music through a metaphor.

Pierre: $\quad$ The sounds of this music [pause] you listen to the sea. You take - how you say it. Coquillage?..

Interviewer: Oh it's a Sea Shell?

Pierre: $\quad$ Sea Shell right... and you hear the sea. Its fluid. It's a flowy type of sound. 
Here, Pierre gives a vivid metaphor of the music as the waves of the sea. One can picture the ebbs and flows, peaks and troughs of the musical performance. To expand on his metaphor, and elaborate on what he describes as "flowy type of sound" the music is like waves. The sonic frequency starts very small and then gradually envelopes the ear only to return to a small and barely present sound. It gradually returns to a greater fullness, but this time as a new wave. Pierre continues:

I'm not a musician, I'm not a musicologist... It seems to me that you don't have high notes, very low notes, It's just fluid. (Pierre)

In the above passage, Pierre analyses the musical range used within the genre. $\mathrm{He}$ attributes the fluidity to the perceived lack of high and low notes in the performance. He notices that the movement of the music is very natural and gradual as opposed to having extremes.

\section{Increase in musical intensity facilitated cognitive experience.}

The music was a little too soft, but after-at the end of the performance you played a little harder, you played a little louder and it was more efficient for me to just try to forget the background noise. (Pierre)

In the above excerpt, Pierre, like Andrew, expresses a level of initial dissatisfaction with the sonic simplicity and lower amplitude of the beginning movement. It appears that in both accounts, the soft music allowed them to be aware of the sounds around the room or what Andrew had described as the "here and now."

Pierre expresses a need for amplitude in the music to detract from his external surroundings. This intensity in the music allows him to forget about the background noise that was previously discussed, be this a physical noise or the presence of cognitive thoughts.

I think the beginning was a little smooth. Suddenly you started to play a bit louder, or maybe I imagined there, or maybe I got more into the music at the end of the performance. (Pierre)

One can see a recurrent theme of the increased intensity of the music allowing both listeners the ability to go away from their "outward" awareness and go further into the inner thought processes or as Pierre states "more into it".

Again, one can see the music as a form of catalyst that guides them towards their preferred mental experience. In the case of Pierre, he expresses that the perception of volume may have been due to the increased amplitude on the instrument, or it may have been perceived 
or 'imagined' as the performance developed. This suggests that he wonders if it was not so much the performance that attuned to him, but his mind that had become attuned to the performance.

\section{Music distancing oneself from present/physical reality.}

It kind of stops it. That's what has a great affect on your mood because you stop thinking about your trouble your career, or your problems there, so such what this music does is to make you stop thinking, so you don't have thoughts as such. In fact the main thing is to make you stop thinking. (Pierre)

In the above passage, Pierre describes a process where the raga stops his ruminating thoughts, including his current problems. In the interview, I attempt to have him elaborate on the phenomenon.

Interviewer: What is it... that makes it stop, would you say.

Pierre: $\quad$ Well it's simple. It makes you stop thinking and the room inside your head is taken by the music, you let yourself be. And that's what the great beneficial effect of this music is, because you stop reminiscing about your problems there, and you just let themusic take over.

Pierre appears to come to a moment of personal realization as he continues to construct meaning in his experience. The music takes over his thought processes, allowing him to yield or give in to the music. This is similar to Andrew's account of the music allowing him to give in. He continues.

It's unbelievable, I don't know, I'm not a music therapist but I believe that it's the best thing for this music. (Pierre)

Here, one can see that Pierre finds a great deal of meaningfulness in the concept of the music taking over his ruminating thought processes.

\section{Emotional/ physiological changes.}

\section{Comparisons to a sleep like state.}

Interviewer: Okay [affirming] .... and you mentioned a sleepiness...Maybe expand on that sleepiness?

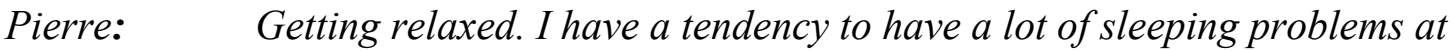
home. So I'm always kind of in a sleeping deficit, so the fact that this music induced a type of relaxation, your mind getting empty. It helped you to become a little bit more sleepy, and it's an effect of relaxation. 
The theme of a sleep like state re-emerges in Pierre's account. In his account, the music allowed his mind to be empty, which then allowed relaxation allowing him to be aware of his naturally tired body. He continues illustrating how meaningful entering into a sleep like state is for him.

I'm sure it's not everyone. So, I guess it means it works. It's a good thing. (Pierre)

Physical sensation. Unlike the other two participants, no apparent physical sensation was present in Pierre's account.

Emotional changes. Pierre, like Andrew, describes a feeling of calm at the end of the experience.

I believe I'm a little bit calmer at the end. Plus maybe the breathing exercise, which was good and also the fact...well the music itself, I'm calmed down. (Pierre)

Here, he attributes this feeling of calm to both the initial induction as well as the music itself. He pauses before mentioning the music. It is as if he is taking a moment to differentiate whether it was the music that allowed this feeling, the induction, or a combination of the two. He continues to express his emotional state.

I'm in a better mood than when I came in the experience. (Pierre)

It appears that Pierre attained his preferred emotional state by the end of the experience. One of his expectations was to feel calmer, and an example of this expectation is explored in the next theme.

\section{Preferred duration of experience.}

For me, to really help me to calm down, it should have been a bit longer than 10-15 minutes... maybe half an hour or so. At the end I was more into it. (Pierre)

In Pierre's account, he feels that the experience could have been longer to allow him to be more fully immersed in the experience.

I understand that you can't play for two hours, it gets a little complicated, so it kind of stops a little abruptly. I think you said, ok this is finished with the music,... [quickly exhales], just trying to let yourself be filled in by the music and then bang, the music stops, - you come back to reality. (Pierre)

Through his words and non-verbal exhalation, Pierre appears to be disappointed by the length of the movement. The quick return to the waking state is almost like a breach in the cognitive holding space that he had achieved in the experience. This experience slightly diverges 
from Andrew who found safety in knowing that the intervention would last 15 minutes. However, in Andrew's account, he found safety in the fact that he had an approximate time for the experience. One wonders if being given a longer approximate time for the experience would still allow for this feeling of safety and allow Andrew, the previous participant, a deeper immersion into the experience.

\section{Zara's Experience}

Zara's account of the experience, as in the previous two accounts, was also analyzed through the same overarching themes and subsidiary themes with particular attention given to her own unique experience.

Initial awareness of sensory stimulation and environment.

"Here and now; presence of the room, people around me, smells..."

I liked the ambience and having the pillows- I think was a really good part of it. (Zara)

Early in the interview, Zara brings up her awareness of the atmosphere of the room.

It was positive because it gives you the option to be on the floor, and be on the seat and I think all the time that we sit on chairs, when we could actually sit on the floor and it's totally fine. So it's nice to be invited to take up as much space as you need. (Zara) Zara also places strong reference to the group, indicating that the presence of the group was a part of the experience. She mentions the multi-cultural nature of the group.

It was a good mix of people too. Cause there was...different nationalities. It was really cool. (Zara)

Although she later found comfort in the group dynamic (explored in a later theme), she also is aware of the people around her at the beginning of the experience.

[S]o at the beginning, I felt people were uptight... (Zara)

This further illustrates how important it is for Zara to be part of an experience with a positive group dynamic. She was very receptive to the social atmosphere within the room at different times in the experience as expressed in her interview.

Physical self. Zara brings attention to her physical self early on in the interview.

I think the position I chose to sit in wasn't the most comfortable but that's not the point of it. I felt honestly, just because my posture was a bit like uneven... (Zara) 
She expresses the common theme of having an awareness of her posture, but feels that the experience had a different purpose other than her physical discomfort. She alludes to the idea that the experience was about something other than physical-sensory awareness.

Pre/ post-contextual thought processes as inherent to the experience.

Presence of past and future thoughts "real thoughts."

Interviewer: So was the music able to illicit any imagery or memories?

Zara: $\quad$ Not really actually,.. I was just kind of thinking about outside [It was snowing]. So I guess I kind of, I saw all of the snow-its just been in my head for a while. I guess images of me walking in the snow I'd say.

As in the other participant's accounts, one can see that pre-existing context was inherent to her experience. For Zara, it was the immediate past context of snow that she brought with her when she entered the experience. The snow could also be a metaphor for the randomness, and relentless busyness that she had brought with her to the experience as she states in a subsequent passage.

Cause were so busy, especially during winter, you just kind of, you get caught in the mess of it all. (Zara)

From this statement, one can envision the hectic nature of winter life or relentless "snow" that is present within her consciousness and how one can get caught in the mess when trying to get from one place to another.

Initial pre-associations with music of sitar/genre. Zara, like the other participants, has pre-associations of the sitar or sitar like music.

I actually had images of Nepal because I've been to Nepal before. It kind of reminded me of Nepal a bit...I'd be in shops and I'd hear music that was kind of similar to that I guess? (Zara)

In the previous statement, Zara describes how her associations with the music are linked to her experience of being in Nepal. Although it may not have been classical Indian raga that she heard in the shops in Nepal, the musical instrumentation appeared to trigger memories of her time there. Like both other participants, Zara associates the instrument/genre with something that most closely resembles this music in her past. 


\section{Raga as trusted guide; the development of a "cognitive holding space" through}

music.

\section{Musical safety while being allowed to mentally explore.}

Just letting my thoughts flow... like having no subjective outlook on it I guess?(Zara)

In this passage Zara mentions how her thoughts were flowing as the music continued. She elaborates.

Interviewer: You mentioned a flowing... Could you maybe expand on that flowing?

Zara: I I Ion't know. Often I stop my thoughts from occurring. Like "No you can't think about this, you have other things to do"

Zara describes that as the music continued, her thoughts increased in flow. However, what was different in this experience is that she felt comfort in allowing these thoughts to continue. This is illustrated in her statement.

I just look on the internet and just ignore them, but this time I had to address and be like

"You have nothing else to do you're here so yeah." (Zara)

One can see an internal dialogue where a voice in her head is calming her, telling her that it is fine to continue with these thoughts. Like in previous participants' accounts, it is as if the musical experience had created an atmosphere in which she felt safety, like a guide who is encouraging her to continue. In Zara's experience, this was to explore thoughts that she might not have in another context. The theme of support enters Zara's account, and unlike the other participants, it is not limited to the music, but to the group experience as well.

I guess with the group it felt like there was less pressure. I've never done music therapy before, I've done therapy once and it's a bit intense, just like talking one on one about your feelings, so it was nice just having other people talking about the same thing and knowing okay, other people are doing it too, they are feeling their own feelings. (Zara) Here, Zara mentions that there was less personal pressure in the experience. One might view the group as united in the fact that they are all part of the same experience. At the same time, as Zara expresses, each person is still "feeling their own feelings." The musical experience in conjunction with the listeners or receiver creates a unifying atmosphere. The music becomes as Andrew stated, the "anchor". To expand this metaphor to a group context, it allows each person support to explore their own feelings or experience. 


\section{Fluidity of the music and thoughts.}

Yeah, I would say...well not faster, just they were just flowing more. I wasn't stopping them. So they would just kind of... they just happened. (Zara)

In Zara's account, she expresses the flowing nature in her thoughts as the raga continued. In her case, she does not specifically address the music as fluid, but her thoughts. However, it is reminiscent of how Andrew described a lack of linearity in the music and in how Pierre compared the music to the sea. Thus, the music created a fluidity of thought is illuminated in all participants' accounts. Zara further explores her feeling of flowing thoughts in the next theme. Increase in musical intensity facilitated cognitive experience.

Zara: $\quad$ I was thinking and my thoughts were coming so rapidly that I was like trying to keep up with myself.

Interviewer: Okay [gently affirming] — so your thoughts were going faster during the performance?

Zara: $\quad Y e a h$, I would say... well not faster, just they were just flowing more.

In the above excerpt, Zara describes how as the performance continues, she notices the streaming movement of her thoughts. One can interpret the emerging of the music to be a catalyst. In Zara's case, this musical catalyst is not guiding her towards a preferred mental experience but facilitating preparation for her mental experience. It appears that the increase in musical intensity or simply the duration of the musical movement is guiding her mental processes.

\section{Music distancing oneself from present/physical reality.}

Just like, seeing my thoughts as thoughts and just kind of like not looking at my cell phone, not looking at the internet cause I get caught up in that and just focusing (Zara). In the above passage, Zara describes a process in the experience where she is no longer avoiding her thoughts through the distractions of everyday, but experiencing a state of transcendence, in taking the thoughts simply as they are. She refers to this in her own words as "seeing outside herself". This is further explored in the next excerpt.

Just being able to relax and just being in my body, without having to think about being in my body-- I guess. (Zara)

In the interview, I attempt to have her elaborate on her construction.

Interviewer: Maybe if you could expand on something... being in your body... 
Zara: $\quad$ I guess escaping my body.

Interviewer: Okay [affirming]

Zara: $\quad \quad \quad Y e a h$, just being able to...I don't know, I don't know if that's the point of it, but when I hear that type of music that's what it reminds me of...like meditation, more yoga, or yeah.

Zara compares the music to Yoga, or meditation; it reminds her of the concept of escaping her body. Something in the experience has given her a feeling of escaping. She is aware of her body, while having a feeling of being outside of it. Again, there is convergence with Andrew's description of having an "[a]nchor," or feeling grounded while "being able to float" within his experience.

\section{Emotional/ physiological changes.}

\section{Comparisons to a sleep like state.}

Like being able to close your eyes and not sleeping pretty much. So you can just kind of take time for yourself. (Zara)

In the above passage, Zara alludes to a phase that is similar to sleep, yet in this phase she maintains a state of awareness. Her mention of "taking time for yourself" gives the impression of meaningful time. This converges with Pierre's account as he also mentions the importance to him in feeling sleepy.

\section{Physical sensation.}

Interviewer: Would you say there were any emotional or sensory changes that happened for you during the experience or while the music was playing?

Zara: $\quad$ Oh my heart was beating faster actually.

In this excerpt, Zara mentions the physiological change of her heart beating faster as her thoughts began to progress. She attributes this to her feeling of excitement as a result of her flowing thoughts. One could again interpret as the dynamic changes in music as facilitating this experience.

\section{Emotional changes.}

Interviewer: Were there any emotional or sensory changes that happened for you during the experience?

Zara: $\quad$ Yeah, I teared up a bit. I started thinking about my relationships. Yeah it was really cool just... kind of seeing what I can fix in my life. yeah. 
Zara's emotional catharsis appears to be a personally significant moment of introspection. In her narrative, she expresses that she had moments of realization in her journey; she found this process interesting. Later, she summarizes her experience.

It was good, yeah. Just being honest with myself. (Zara)

One can see a cathartic release in her words. Earlier in the interview, she mentions her overall experience.

I would say it was a positive experience just because of how beautiful it sounded. (Zara)

From this statement, one can assess her experience to have been aesthetically pleasing. She does not express a feeling of calm as in the previous two participants, but appears to have reached an emotional state that is satisfactory to her at the end of the experience. She speaks to her desired state of being in the next theme.

\section{Preferred duration of experience.}

Interviewer: And if there were a length that would be - an ideal length for you? You mentioned a length.

Zara: $\quad$ I would say 45 minutes probably, or an hour.

Interviewer: Okay-And why would that be?

Zara: $\quad$ Just because I could expand more. Cause I haven't really gotten into meditation, but I hear if you go deep into it you can just think about nothing. But maybe that's ... making it more simple than it is [laughs]. But just kind of getting into that state of peacefulness.

Zara converges with Pierre in that she felt that the experience could have been longer and allowed her to become more fully immersed in the experience, to fully reach a desired state of mind. She compares it to a meditative experience where the duration may be longer than 15 minutes. As in Pierre's experience, she discusses her disappointment when the experience stopped.

Interviewer: And what was the feeling like when it stopped. What was that feeling like for you?

Zara: $\quad$ Um... I don't know. It kind of felt like, not the end of a journey, but it was, just like the way you played it, it was kind of like trinkling off and it was... like the end of a movie,... it felt like the wrapping up of.. an experience .. But the feeing, no [pause.] I don't know what the feeling would be. 
Interviewer: Can you think of a word?

Zara: $\quad$ I would say just disappointed because I liked it, yeah [laughs].

As in Pierre's account, there is a feeling of disappointment or even sadness in the end of the experience. 


\section{Chapter 5: Discussion}

In this Discussion section, the key findings are presented and organized according to the research question. The relevant overarching themes and subsidiary themes that evolved in relation to the research question are also explored, while findings are related to the existing literature. I also explore personal reflections of the phenomenon through my perspective as the performer. The limitations of the study are addressed, suggestions for future research are explored, and potential clinical applications of the results are identified.

\section{Pre/Post-Contextual Thought Processes as Inherent to the Experience}

Stige (2007) asserts that people bring their own individual and intertwining contextual factors to musical experiences. It is evident that the research participants brought with them their personal thoughts from prior to the experience (Zara and Pierre) as well as their preconceptions of what the experience itself would be like (Andrew). When the participants were asked if the experience reminded them of anything, answers were based upon pre-existing experiences with the music. They associated the music to times in their past when they had heard similar-sounding music, such as in the shops in Nepal (Zara), movies depicting India (Pierre), and childhood memories of the music (Andrew).

As Stige (2007) affirms, the individual might connect to particular music in different ways and for various reasons that are unanticipated (Stige, 2007). For example, Andrew compared the beginning of the initial movement to folk. He felt the initial moments where the form of the raga was exposed (Viswanathan, 1977) had an unexpected sense of familiarity to him. It is interesting to note that Raga Desh loosely translates to "homeland" (U. Neumann, personal communication, Feb 1, 2009); it is known throughout various regions of the multicultural landscape encompassing India. Zara linked her experience to exploring past personal relationships. It appears that some individuals may share the symbolic representation of the raga, as in the case of Andrew and Zara.

As previously mentioned, the raga is known to evoke feelings of romance and personal longing. This adds insight into the empirical hypothesis that when experiencing certain modes, individuals may share psychophysical emotional responses regardless of familiarity with the genre (Balkwill \& Thompson, 1999). Ragas (with their specific tonic intervals, tonality, rhythm, and tempo) have been found to evoke distinct emotions in the listener (Sundar \& Parmar, 2016). The BRECVEM model (Juslin, Liljestrom, Vastfjall, \& Lundqvist, 2010) 
identifies seven mechanisms by which music can induce an emotional response. Some of these require the listener being familiar with the music. However, amongst the seven, rhythmic entrainment, emotional contagion (where the listener interprets the emotional expression of the music and mirrors the emotion internally), and visual imagery are not dependent on the listener's familiarity with the music. It is possible that these three mechanisms are particularly at play in the context of their experiences.

At times, the music challenged preconceptions. Andrew described how he was expecting the beginning to be louder. This could be attributed to the participant's preconceptions of the musical performance. The intention of the raga was not to grab the listeners in the beginning, but to be part of the sounds of the room and as Andrew stated, gradually "draw the listener in". This may differ from some Western classical traditions. For example, Schafer (1969) describes how diverse works such as those of Beethoven, Stockhausen, and Berlioz at times aim to surprise the listener. This idea paints a picture where the overlying stylistic element or compositional intention is one of extremes, or tension and release. Similarly, Menuhin \& Davis (1979) allude to the philosophical divergence between Western classical and raga traditions. In the latter, the intention of the music is not to take people through a showcase of emotional states, but rather to focus on one specific mood and the variations within it.

Other participants found similarities to Western classical music. One participant (Pierre) found both mediums to share a fluid nature, reminiscent of the sounds of a coquillage (seashell). In attempting to interpret the moments of music that he was describing, Pierre's words are reminiscent of the $20^{\text {th }}$ century minimalist composer Steve Reich's manifesto (1968) on playing and performing in a gradual music process:

Performing and listening to a gradual musical process resembles:

(...) turning over an hour glass and watching the sand slowly run through the bottom; placing your feet in the sand by the ocean's edge and watching, feeling, and listening to the waves gradually bury them. (p. 304)

This passage gives a sense of the fluid and wavelike nature in Reich's compositional process through a listening and playing experience. The similar fluidity of the raga and how it may have led the participants toward a mindful state will be further explored later in this discussion. 


\section{Raga as Trusted Guide; The Development of a "Cognitive Holding Space" Through Music}

In discussing the role of music in Guided Imagery and Music, Bruscia (2015) describes the difference between "music as transformation" and "music in transformation" ("The Role of Music in the GIM Process," para. 1). With music in transformation, the music plays a subsidiary role to verbal processing facilitated by the therapist. In music as transformation, the music becomes the primary therapist, guiding the listener through her/his experience with little reliance on other therapeutic mediums such as verbal modalities or other creative arts (Bruscia, 2015). As this experience relied predominantly on the music (absence of verbal suggestion during the musical experience), it is interesting to note that participants described the elements of the music to be a trusted guide, slowly creating a cognitive holding space for participants to mentally explore.

Musical safety while being allowed to mentally explore. All participants expressed a feeling of safety as they could let themselves and their thoughts give in to the music. For Andrew, the music was described as caring, in that it allowed sonic space in the initial exposition. In Pierre's account, the music did not overly demand or divert his attention allowing for his thoughts to flow freely. For Zara, the musical experience allowed an internal dialogue encouraging her to safely continue with moments of introspection. Kenny (2006) discusses the "musical space" (p. 476) as a contained area where the client and therapist engage in exploration through musical interaction. Vital to this container is a feeling of safety, which allows thoughts and representations to emerge in a fluid and spontaneous manner. Although the present experience was a receptive one, where group members were listeners and not part of the improvisation, one could relate the feeling of safety in the listeners as expressed in their fluid mental explorations. In this instance, the music provided a safe cognitive space for the participants to mentally explore within the acoustic confines of the experience.

Support in experience. All participants expressed support in the experience. For Pierre, the music was the "support for feeling better" as he felt "strong by something soft". Andrew used the metaphor of the duration of the experience as an anchor. Furthermore, as Andrew stated, "something" instilled a feeling of grounding, a sense of support while the buoyant music allowed the participants to float away in exploration (Andrew and Pierre). The literature mentions how the tonic drone creates musical environment allowing for various melodic possibilities to occur (Powers, 1958; Dona, 2012). One could interpret the tonic drone of the music as the sense of 
grounding, something to support them throughout the melodic explorations. One can envision the drone as a constant tonal presence for the participants over a canvas of time. Zara felt comfort in the group experience; for her, the musical experience linked the group, allowing for participants to explore their own individual thoughts. It appears that the raga was what Kenny (1985) describes of music in general as "the connective tissue guiding [one] into wholeness" (p. 9). Perhaps participants all metaphorically shared the anchor, which represented the moment in time of the phenomenon, and were attached to the support rope of music, as they embarked on their own personal explorations.

Fluidity of the music and thoughts. The correlation between fluidity of music and thoughts is illustrated in the participants' accounts. Throughout the duration of the experience, one participant expressed the music stretching thoughts (Andrew), while another compared it to the fluidity of the sea where he could "float away", (Pierre). The third participant felt the flow of her thoughts increasing as the music continued. Here one can see a cerebral plasticity that takes place over the course of the experience. Pierre describes the lack of high notes and low notes in the raga as allowing a sense of fluidity. The Canadian composer Shaffer (1969) describes how in Western classical music up until the Renaissance period, the range of the human voice, (effectively 100 cycles to 1,000 cycles), was a limitation that most composers intentionally or subconsciously adhered to. With the advent of new instruments, compositions began to exceed this sonic range. Schafer (1969) expresses that instruments that stay within this range have a familiar and poetic quality. Although the range of the sitar is between 250 to 2000 cycles (Ranade, 1964) and subsequently higher depending on tuning and stringing, it is possible that the relatively limited range of the sitar attributed to the lack of low notes and high notes, or "fluidity" that Pierre is describing.

One might also interpret Pierre's observation of fluidity as a lack of extreme intervals or leaps present in the music. In raga, the ascension and descent of notes is approached systematically and gradually. Notes are approached in multiple ways and through subtle yet intricate tonal bends. The musical contour is based upon what again might naturally be sung by the voice. (Rao, 2014) describes the melodic phrases of a raga as a "gestalt" (p. 4) with infinite yet minute elaborations on the motif in a continuum of tonal curves and variations while still adhering to the grammatical structure of the raga. 
Increase in musical intensity facilitated cognitive experience. Participants recalled wanting the music to be louder at the beginning of the performance (Andrew, Pierre). As the player in this experience, there were factors attributing to this perceived quietness. First, in the beginning of the performance, I was calibrating with the instrument, the acoustics, the environment as well as the amplification device. Secondly, in the first movement prior to the initial exposition of the theme or basic raga structure, I stylistically used subtle ornamentation through string bending and hammer-off grace notes (krintan) to bring attention to the resonating sympathetic strings. I purposefully added pauses between musical phrases to allow the silence to resonate. This is characteristic in Alap, but varies according to the musician's style. As previously stated, the Alap movement is not explicitly taught, but internalized through teacher student interaction (Ruckert, Khan, \& Khan, 2009). The second attribute to the low volume was my intention to musically meet the atmosphere of the room, to not start in overly intrusive (sonically present) manner. My own mood was part of this assessment of the atmosphere. I did not initially have the level of confidence that I might have had in another time and setting to establish more of a sonic presence. A less sonically intense beginning is also intrinsic to the natural form of the raga. At the same time, it corresponds with the iso principle (Altshuler 18931968) where one meets the participants emotionally and/ or physiologically while gradually raising or lowering the intensity of the music to facilitate a desired mood (Davis, 2003).

Similarly, the presence of the music guiding the experience is inherent to the participant's accounts. Andrew's description of the musical dynamics appears to follow the contour of the musical movement of the experience. In the beginning of the experience, he describes how the music began more quietly and was less ornamented, and thereby focused his attention. This is representative of how Sairam (2006) observes that the slower rhythms and tempos of raga decrease cognitive processing speed. It then gradually drew him more into a repetitive rhythm. The repetitive rhythm that he describes could be interpreted as the second movement that I played within the Alap, the jhala, or movement with rhythmic ostinato. The ostinato is attained by plucking the top (chickari) strings with the picking hand while continuing with melodic variation in the right hand (Caudhurī, 2000). The final movement that I played was the jhor, which was the faster movement. It is accompanied by sonic and rhythmic complexity through plucking the chikari and creating volume swells as the player elaborates and experiments with rhythm while revisiting the initial phrases and motifs (Slawek, 1998). One could interpret this as the area where 
one participant describes her thoughts as flowing more as well as her heart beating faster during the performance (Zara); where at one point she struggled to "keep up with herself." One can see a form of entrainment between the participant and the music. As Clayton, Sager, and Will (2004) describe, the oscillations of the music began to match the oscillations of the Zara's physical and mental processes. In this movement, a drone begins to permeate from the instrument as a result of the consistent ostinato of the right hand picking (Caudhurī, 2000). Kenny (2006) notes that continuous ostinato in music can create a trance state and facilitate one entering a non-ordinary state of consciousness. This increase in intensity and melodic movement appears to be what replaced the noises in the room in what Pierre described as "more efficient" for him to become calm and what Andrew described as allowing him to move towards an inward state. Bruscia (2015) discusses conditions for clients to enter or remain in a non-ordinary state of consciousness in GIM sessions. Individuals may experience difficulty with atonal and inconsistent melodies (Bruscia, 2015). Although these characteristics would be unique to the cultural and personal context of the individual, the melodic ascending and descending rules or "givens" inherent to the raga may have contributed to their cognitive experiences.

Music distancing oneself from present/physical reality. The use of raga for meditation experiences is mentioned as a potential application for this genre within the music therapy literature (Moreno, 1988). The participants described a state where the musical experience allowed them to leave their outward states and move inward (Andrew) and thus, escape much of the physical awareness of their bodies (Andrew and Zara). This state of mind was one where they were not overwhelmed by present thoughts like problems in their career (Pierre) or in need of distraction, like looking at the Internet (Zara). The group's experience is reminiscent of mindful meditation. Furthermore, two participants allude to the practice within their interviews (Zara and Andrew). In mindfulness, one attains awareness through noticing experience in a non-judgmental or reactive manner over time (Miller, Fletcher \& Zinn, 1995). Similarly, throughout the course of the experience, the music appeared to stop Pierre's previous thought processes or as Zara described, she could accept thoughts as thoughts.

\section{Emotional/ Physiological Changes}

All participants expressed having experienced cathartic release during the performance. For two of the participants (Andrew and Pierre), it manifested itself as a feeling of sleep-like calmness. This is consistent with Sairam's (2006) claim that the slow and hypnotic patterns of the 
raga are conducive to feeling relaxed and calm. One participant linked the calmness to a feeling of warmth and freedom (Andrew) as reflected in his imaging experience. In a study on participants' experiences of a GIM session (Bruscia, 2005), participants listened to Ravel's Introduction and Allegro (Ravel, 1905). As in Sairam's description of raga, Bruscia (2005) describes the slow patterns of the fourth section of Ravel's cadenza as calming tensions. $\mathrm{He}$ describes that the pauses or spaces in the cadenza allowed a sense of wonder as to where the music will go for participants (Bruscia, 2005). Accordingly, participants predominantly responded with feelings of self-reflection, visual imagery and emotion (Bruscia, 2005). When listening to Ravel's Cadenza (Ravel, 1905), the section's slow and improvisational like freedom accompanied by the presence of space and resonant plucking of strings appears to share similarities with the alap movement of a raga. At the same time, the Cadenza is a relatively short segment placed between other movements encompassing frequent changes of tempo and mood.

The idea of rasa in raga, where the individual attains some form of enlightenment through the aesthetic beauty of the experience (Dona, 2012) may be related to Zara's experience. Although I am not attempting to determine a causal relationship, or even a correlation between beauty and enlightenment in a phenomenological analysis, it is interesting to note that in addition to expressing that the music evoked tears during moments of introspection, she also reported multiple times in her account of the aesthetic beauty of the music.

\section{Preferred Duration of Experience}

All participants reflected on the duration of the experience. Two participants felt the musical experience could have been longer than 15 minutes and expressed disappointment when the experience was over. One participant found safety in knowing that the experience was 15 minutes (Andrew). From my own perspective as the player in the experience, in the moment, I would have liked the musical segment of the experience to go longer. When the experience is improvised in a live setting, the musician will decide in the moment how long the experience might be (Viswanathan, 1977; Ruckert, Khan, \& Khan, 2009). Often, a raga can stretch the perception of time for the listener (U. Neumann, personal communication, May 10, 2009); as noted earlier, the experience can go anywhere from 3 minutes to many hours (Viswanathan, 1977). However, the assisting fellow magisteriate student was directed to inform me at the 14 minutes' mark to complete the experience in order to comply with the pre-determined design. 


\section{Summary of Limitations}

There were limitations inherent in the design of the study. The improvisation was live and

mistakes in the performance could not be accounted for. The experiences of the participants could not be generalized to the experiences of raga that clinical populations may have in music therapy settings. Nor could participants' experiences of the particular raga (Desh) be generalized to participants' experiences of other ragas. The unique timbre of the sitar, as well as its perceived novelty could not completely be separated from the listening experience of the raga. I am aware that the performer, myself, was also the researcher and involved in aspects of the data collection process, so there was a possibility for researcher bias. To account for this, an epoché was written where my biases were acknowledged to the best of my ability and bracketed at many points during the analysis process. Furthermore, although participants were asked to be as objective as possible prior to the interview, there may have been a greater chance of participant response bias and lack of full participant disclosure as the interviews were face to face and conducted by myself in my capacity as both researcher and performer. It is also apparent that the interview schedule would have affected the participant responses, and consequently, some of the themes that emerged. At the same time, efforts were made to keep the first question very general and to take notes on any unanticipated themes that may have emerged. Later, I revisited these topics in the interview. In addition, extreme care was taken not to lead the participants towards particular answers.

\section{Implications for Further Research}

As the current research was exploratory in nature and little previous research has been done with non-active listeners of raga in non-clinical music therapy settings, one can see potential for further research. The raga played during the experience was Desh, which is one among many known ragas (Kaufmann, 1968). The research only looked at the Alap movement within a raga. The instrumentation used in the study was the sitar. Participants' experiences of various ragas when played on different instruments including the voice could also be explored. Further research could look at the experiences of individuals after receptive music therapy interventions using other ragas, as well as different movements within the raga. Future research could look at how participants respond to different ragas in both slightly non-ordinary and ordinary states. A study comparing the use of different ragas within a single sample group could be particularly useful. 
Similarly, it would beneficial to understand participants' perceptions of raga over the course of multiple interventions (as opposed to the single intervention design used in the present research).

During the experience, participants mentioned feelings of mindfulness and related the experience to meditation practices. Further research looking at what aspects of the raga experience heightened awareness or mindfulness in participants is warranted. One of the prevailing overarching themes that emerged from the experience was the music creating a safe and supportive "cognitive holding" space for participants. The research began to illuminate conditions in the music that allowed for this phenomenon. A phenomenological research further investigating the elements of the experience that allowed participants to find guidance and safety in the music is recommended.

Some of the participants expressed that the musical portion of the experience could have been longer. Consequently, it would be relevant to investigate the effect of diverse duration of the music on participants' experience. Likewise, the induction in this experience was brief, to account for ethical considerations and participants might not have been in a deep non-ordinary state as in other forms of induction.

Further understanding raga might contribute to the general understanding of other genres of music and the intention of its composers, as well as why and how specific moods may be evoked for listeners who are unfamiliar with these genres. Research in the field is also warranted in understanding the experiences after a receptive raga intervention for populations ranging from geriatric to mental health settings, as well as other populations of diverse cultural backgrounds.

\section{Potential Clinical Implications/Reflections}

It is not the intention of the study to generalize the experiences of three participants in a non-clinical setting to the field of music therapy. The following implications are reflective in nature. Although raga is being used in clinical settings in India as well as in other parts of the world, the research brings new light as to how receptive raga intervention could be beneficial to clients in visualization, relaxation, as well as mindfulness experiences.

Participants in this research intuitively established connections between the musical experience and mindfulness. Within the field, Regulative Music Therapy (RMT) is a form of receptive therapy that uses mindfulness practices to regulate unnatural stress related tensions in body and mind (Moridaira, 2011; Schwabe, 2007). Currently, this method uses predominantly Western classical music in the context of the receptive experiences. Incorporating raga with RMT 
may be warranted as raga may inherently facilitate one's exploration of mindful states of awareness.

Allowing clients to be in a slightly non-ordinary/ relaxed state during receptive raga experiences may prove effective within the clinical setting. As previously mentioned, receptive raga experiences using Alap movements, particularly Desh, could be facilitated with a music therapist as leader and a classically trained musician as co-leader. As the Alap is improvised, the live musician/participant interaction might allow a personal and dynamic therapeutic experience; the music might act as a guide or "primary therapist" with opportunities for verbal processing at the end of sessions. As having a classically-trained raga musician in session may be logistically difficult, the music therapist could select recordings of ragas in the Alap movement. Receptive experiences may be advantageous in group settings as the client would feel support from the group, as well as be part of a shared listening experience

It should be noted that certain ragas are traditionally played at certain times of day although this is more specific to North Indian raga tradition. This has also been described as the Time Theory of Ragas (Sundar, Durai, \& Parmar, 2016). For example, Desh is traditionally played in the late evening/night time. However, in modern times and in my own experience, ragas are commonly played at anytime of day. Consequently, when working with participants, one is well advised to maintain a clinical sensitivity as to the length of the raga, the mood and associations that the raga has been said to evoke, as well as the cultural background and personal preference of the client.

This receptive raga intervention appeared to not overly attract the listener's attention or take them through extremes in emotional states. This might facilitate experiences where the goals might be emotional regulation, relaxation, or allowing clients to reach sleep like states.

As the flow of the music is fluid and gradual, yet builds in intensity, Alap might also lend well to interventions promoting feelings of empowerment or visual journeys where a client's goal is to attain a profound introspective state. The abstract melodic nature of the Alap movement, while still modally structured and over a tonic-dominant drone, might allow clients a safe space to explore their cognitive processes. The music may trigger new and at times, less predictable associations without overwhelming the client. Thus, a receptive raga intervention may provide participants with the opportunity to gain insight through a unique aesthetic experience: an avenue that may lead to meaningful therapeutic work. 


\section{Final Thoughts}

In closing, I reflect on the universal nature of raga. Lee and Houde (2011) discuss how raga in its highly evolved nature, philosophically, spiritually, as well as technically can influence a Western musician to view sound in a different manner. I would add that this music might allow any musician to view sound differently regardless of cultural background. While playing, understanding, and/or appreciating this music is not always intrinsic, when one is immersed in the form, it can change her/his worldview. Furthermore, Clayton (2001) remarks on the importance of attaining deeper understanding of raga from those who do not consider themselves authorities in either Eastern or Western music. The unique and full experiences of the three individuals after the receptive raga experience are steps towards new understanding of raga. It may also add to the dialogue towards a universal conception of music and sound. Participants put their own lives and worldviews into the meaning making of their experiences. Age-old concepts such as bhava (or the musical expression) and how it affects rasa (or attunes the mind and body) become less distant and begin to intercept with current discourses about entrainment, musicking, music cognition, and music theory (Clayton, 2001). Thus, further understanding raga and its complex and refined conception of healing, music and sound may give new insight into both our musical and non-musical selves. 


\section{References}

Balkwill, L.-L., \& Thompson, W. F. (1999). A cross-cultural investigation of the perception of emotion in music: Psychophysical and cultural cues. Music Perception: An Interdisciplinary Journal, 17(1), 43-64. http://doi.org/10.2307/40285811

Bonny, H. L. (1999). Music and consciousness. Nordic Journal of Music Therapy, 8(2), 171-179. doi:10.1080/08098139909477971

Bowling, D. L. (2013). A vocal basis for the affective character of musical mode in melody. Frontiers in Psychology, 4. doi:10.3389/fpsyg.2013.00464

Bowling D. L., Sundararajan J., Han S., \& Purves D. (2012). Expression of emotion in Eastern and Western music mirrors vocalization. Plus One, 7(3), e31942. doi:10.1371/journal.pone.0031942

Bruscia, K. (2015). Notes on the practice of Guided Imagery and Music. Dallas, TX: Barcelona.

Bruscia, K. (2014). Defining music therapy. (3rd ed.). Gilsum, NH: Barcelona.

Bruscia, K. (2005). A collaborative heuristic analysis of imagery-m: A classical music program used in the Bonny Method of Guided Imagery and Music (BMGIM). Qualitative Inquiries in Music Therapy, 2, 1-35. Retrieved from http://www.barcelonapublishers.com/resources/QIMTV2/QIMT20052(1)Brusciaetal.pdf

Brown, J. M (2002). Towards a culturally centered music therapy practice. Voices: A World Forum for Music Therapy, 2(1) 1504-1611. doi. org/ 10.15845/voices.v2i1.72

Caudhurī, V. R. (2000). The dictionary of Hindustani classical music (Vol. 8). Delhi, IN: Motilal Banarsidass Pub.

Clayton, M. (2001). Introduction: Towards a theory of musical meaning (in India and elsewhere). British Journal of Ethnomusicology, 10(1), 1-17. doi:10.1080/09681220108567307

Clayton, M., Sager, R., \& Will, U. (2004). In time with the music: The concept of entrainment and its significance for ethnomusicology. Retrieved from http://www.open.ac.uk/Arts/experience/InTimeWithTheMusic.pdf

Collier, W. G., \& Hubbard, T. L. (2001). Musical scales and evaluations of happiness and awkwardness: Effects of pitch, direction, and scale mode. The American Journal of Psychology, 114(3), 355-375. http://doi.org/10.2307/1423686 
Cook, P. M., \& Cook, P. M. (1997). Sacred music therapy in North India. The World of Music, 39(1), 61-83. Retrieved from http://www.jstor.org/stable/41699130

Davis, W. B. (2003). Ira Maximilian Altshuler: Psychiatrist and pioneer music therapist. Journal of Music Therapy, 40(3), 247-263. doi:10.1093/jmt/40.3.247

Dona, L. M. K. (2012). On the therapeutic aspects of Indian classical music. Musik-, Tanz Und Kunsttherapie, 23(1), 8-14. doi:10.1026/0933-6885/a000069

Deshmukh, A. D., Sarvaiya, A. A., Seethalakshmi, R., \& Nayak, A. S. (2009). Effect of Indian classical music on quality of sleep in depressed patients: A randomized controlled trial. Nordic Journal of Music Therapy, 18(1), 70-78. doi:10.1080/08098130802697269

Forney, K., \& Machlis, J. (2007). The enjoyment of music: An introduction to perceptive listening. New York, NY: Norton.

Glass, P. (1990). Ragas in minor scale [Recorded by Ravi Shankar \& Philip Glass]. On Shankar \& Glass: Passages [CD]. Berlin, DE: BMG Entertainment.

Grocke, D., \& Wigram, T. (2007). Receptive methods in music therapy: Techniques and clinical applications for music therapy clinicians, educators and students. Philadelphia, PA: Jessica Kingsley.

Harrison, G. (2009). Within you without you [Recorded by The Beatles]. On Sgt. Pepper's Lonely Hearts Club Band [CD]. London, UK: EMI Records Ltd. (1967)

Juslin, P.N., Liljestrom, S., Vastfjall, D., \& Lundqvist, L.O. (2010). How does music evokes emotions? Exploring undelying mechanisms. In P.N. Juslin, \& J.A. Sloboda (eds.), Handbook of Music and Emotion: Theory, Research, Applications (pp. 605-642). Oxford, UK: Oxford University Press.

Kaufmann, W. (1968). The ragas of North India. New Delhi, India: Indiana University Press.

Kaufmann, W. (1965). Rasa, raga-mala and performance times in North Indian ragas. Ethnomusicology, 9(3), 272-291. doi:10.2307/850238

Kenny, C. (2006). Music \& life in the field of play: An anthology. Gilsum, NH: Barcelona.

Kenny, C. B. (1985). Music: A whole systems approach. Music Therapy, 5(1), 3-11.

Khan, S. P. (2005). Raga Desh. On Ustad Shahid Parvez-Live! [MP4]. Kolkata India: Rhyme Records.

Lee, C., \& Houde, M. (2011). Improvising in styles: A workbook for music therapists, educators, and musicians. Gilsum, NH: Barcelona. 
Lester, S. (1999). An Introduction to Phenomenological Research. Retrieved from https://www.rgs.org/NR/rdonlyres/F50603E0-41AF-4B15-9C84-

BA7E4DE8CB4F/0/Seaweedphenomenologyresearch.pdf

McLaughlin, J. (2001). Miles beyond [Recorded by Mahavishnu Orchestra]. On Birds of Fire [CD]. Paris, FR: Sony Music Entertainment. (1973)

Meadows, A. (2010). The evolution of GIM programming. Voices: A World Forum for Music Therapy, 10(3). doi:10.15845/voices.v10i3.497

Miller, J. J., Fletcher, K., \& Kabat-Zinn, J. (1995). Three-year follow-up and clinical implications of a mindfulness meditation-based stress reduction intervention in the treatment of anxiety disorders. General Hospital Psychiatry, 17(3), 192-200. doi: 10.1016/01638343(95)00025-M

Miner, A. (2004). Sitar and sarod in the 18th and 19th centuries (Vol. 7). Delhi, India: Motilal Banarsidass.

Monk, G., Winslade, J., \& Sinclair, S. (2008). New horizons in multicultural counseling. Thousand Oaks, CA: Sage.

Menuhin, Y., \& Davis, C. W. (1979). The music of man. London, UK: Macdonald and Jane's. Moreno, J. (1988). Multicultural music therapy: The world music connection. Journal of Music Therapy, 25(1), 17-27. https://doi.org/10.1093/jmt/25.1.17

Moridaira, N. (2013). Using regulative music therapy at a college counseling center in Japan. Music Therapy Today, 9(1), 212-213.

Ng, Wai Man. (2017, June). Promoting music and imagery through live Chinese music and Chinese GIM programs. Poster presented at the meeting of the 24th Association for Music and Imagery International Conference, Montreal, Canada. Poster description retrieved from https://ami-bonnymethod.org/images/uploads/AMI.Presenters.description.pdf

Nizamie, S. H., \& Tikka, S. K. (2014). Psychiatry and music. Indian Journal of Psychiatry, 56(2), 128. doi: 10.4103/0019-5545.130482.

Nunn, A. L. (2010). Eating disorder and the experience of self: An interpretative phenomenological analysis (Doctoral dissertation). Retrieved from http://uhra.herts.ac.uk/handle/2299/4513

Powers, H. S. (1958). Mode and raga. The Musical Quarterly, 44(4), 448-460. Retrieved from http://www.jstor.org/stable/740707 
Ramos, D., Bueno, J. L. O., \& Bigand, E. (2011). Manipulating Greek musical modes and tempo affects perceived musical emotion in musicians and non-musicians. Brazilian Journal of Medical and Biological Research, 44(2), 165-172. doi:10.1590/s0100$879 \times 2010007500148$

Ranade, S. G. (1964). Frequency spectra of Indian music and musical instruments. Research Department, All India Radio, New Delhi.

Rao, P., Ross, J. C., Ganguli, K. K., Pandit, V., Ishwar, V., Bellur, A., \& Murthy, H. A. (2014). Classification of melodic motifs in raga music with time-series matching. Journal of New Music Research, 43(1), 115-131. doi:10.1080/09298215.2013.873470

Reich, S. (1968). Music as a gradual process. Writings on Music, 1965-2000, 34-36. doi:10.1093/acprof:oso/9780195151152.003.0004

Ruckert, G., Khan, U. A., \& Khan, A. A. (2009). The classical music of North India: The music of the Baba Allauddin Gharana as taught by Ali Akbar Khan at the Ali Akbar College of Music. New Delhi, IN: Munshiram Manoharlal.

Rumball, K. (2010). The effects of group musical activity on psychiatric patients in India. Voices: A World Forum for Music Therapy, 10(2). doi:10.15845/voices.v10i2.164

Ruud, E. (2013). Can music serve as a “cultural immunogen”?: An explorative study. International journal of qualitative studies on health and well-being, 8(1), 20597. http://dx.doi.org/10.3402/qhw.v8i0.20597

Sairam, T. V. (2006). Melody and rhythm: "Indianness" in Indian music and music therapy. Music Therapy Today, 7(4), 876 - 891.

Schafer, R. M. (1969). The new soundscape. Ontario, CAN: BMI Canada Limited.

Schwabe, C. (2007). Regulatory music therapy (RMT). Milestones of a conceptual development. In I. Frohne-Hagemann (ed.), Receptive Music Therapy: Theory and Practice (pp. 203210). Wiesbaden, DE: Reichert Verlag.

Sharma, L. \& Chakroborty, D. (2017, July). Hindustani music as a tool for stress relaxation medium for aged people. Workshop presented at the $15^{\text {th }}$ World Congress of Music Therapy of the World Federation of Music Therapy, Tsukuba, JP. 
Sharma, M., \& Jagdev, T. (2012). Use of music therapy for enhancing self-esteem among academically stressed adolescents. Pakistan Journal of Psychological Research, 27(1), 53-64. psychology of health and illness. Material discourses of health and illness, 68-91.

Slawek, S. (1998). Keeping it going: Terms, practices and processes of improvisation in Hindustani Instrumental Music. In B. Nettl \& M. Russell (Eds.), In the course of performance: Studies in the world of musical improvisation (pp. 335-368). Chicago, IL: University of Chicago Press.

Juslin, P.N., Liljestrom, S., Vastfjall, D., \& Lundqvist, L.O. (2010). How does music evokes emotions? Exploring undelying mechanisms. In P.N. Juslin, \& J.A. Sloboda (eds.), Handbook of Music and Emotion: Theory, Research, Applications (pp. 605-642). Oxford, UK: Oxford University Press.

Smith, J. A., Flowers, P., \& Larkin, M. (2009). Interpretative phenomenological analysis: Theory, method and research. Thousand Oaks, CA: Sage.

Smith, J. A. \& Osborn, M. (2008). Interpretative phenomenological analysis. In J. A. Smith (Ed.), Qualitative Psychology (2nd ed., pp. 53-80). Thousand Oaks, CA: Sage.

Smith, J. A. (1996). Beyond the divide between cognition and discourse: Using interpretative phenomenological analysis in health psychology. Psychology \& Health, 11(2), 261-271. doi:10.1080/08870449608400256

Stige, B. (2007). The Grieg effect: On the contextualized effects of music in music therapy. Voices: A World Forum for Music Therapy, 7(3). doi:10.15845/voices.v7i3.548

Straehley, I. C., \& Loebach, J. L. (2014). The influence of mode and musical experience on the attribution of emotions to melodic sequences. Psychomusicology: Music, Mind, and Brain, 24(1), 21-34. doi:10.1037/pmu0000032

Sundar, S., \& Parmar, P.N. (2016). Music Therapy: Bridging traditional healing system and modern science. Ann. SBV, 5(2), 33-35.

Sundar, S. (2007). Traditional healing systems and modern music therapy in India. Music Therapy Today, 8(3), 397-407.

Sundar, S. (2005). The ancient healing roots of Indian music. Voices Resources. Retrieved from http://testvoices.uib.no/community/?q=country/monthindia_march2005a 
Sundar, S., Durai, P., \& Parmar P. N. (2016) Indian classical music as receptive music therapy improves tridoshic balance and major depression in a pregnant woman. International Journal of Ayurveda and Pharma Research, 4(9), 8-11.

Viswanathan, T. (1977). The analysis of Rāga alāpana in South Indian music. Asian Music, 9(1), 13-71. http://doi.org/10.2307/833817 
Appendix A

Recruitment Poster

\section{RESEARCH PARTICIPANTS WANTED \\ Participants' Experiences of a Receptive Music \\ Therapy Intervention that Incorporates Raga}

Principal Investigator: Stephen Venkatarangam, MTA, MT-BC

Goal of the Research: To examine the experiences of participants after attending a single live musical performance of classical Indian music (Raga).

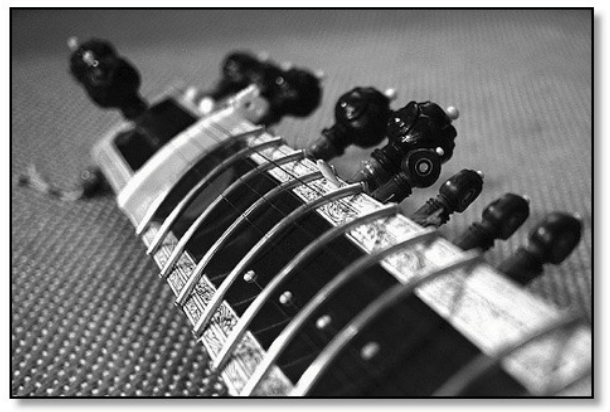

Full participation in this study involves: Participating in a single session receptive experience, which will include a breathing relaxation induction, followed by a live classical Indian music performance on sitar. After the experience, you will be asked to take part in a brief exit interview (Total duration: 45-90 minutes depending on post interview timeslot).

\section{Participant Inclusion Criteria:}

- Be 18 years or older

- Have no previous or current mental health issues

- Not be on any anti-anxiety or mood altering medications

- Not actively play or listen to raga

- Be proficient in the English language

For more information about this study, or to volunteer for this study, please contact:

Stephen Venkatarangam, MTA, MT-BC

514-619-0582

Email: Steve.Venk@gmail.com

This study has been reviewed by, and received ethics approval through the Concordia University Research Ethics Committee. 
Appendix B

Information and Consent Form

\section{INFORMATION AND CONSENT FORM}

Study Title: Participants' Experiences of a Receptive Music Therapy Intervention that Incorporates Raga.

Researcher: Stephen Venkatarangam, MTA, MT-BC

Researcher's Contact Information: (5I4) 6I9- 0582; Steve.Venk@gmail.com

Faculty Supervisor: Dr. Sandra Curtis

Faculty Supervisor's Contact Information: sandi.curtis@concordia.ca

\section{Source of funding for the study: N/A}

You are being invited to participate in the research study mentioned above. This form provides information about what participating would mean. Please read it carefully before deciding if you want to participate or not. If there is anything you do not understand, or if you want more information, please ask the researcher.

\section{A. PURPOSE}

The purpose of the research is to examine your experience of a single live musical performance of classical Indian music (Raga). This study hopes to contribute to the field of music therapy practice by providing insight into people's experience of this musical style.

\section{B. PROCEDURES}


If you participate, you will be asked to attend a single session receptive experience, which will include a 5-minute breathing relaxation induction, followed by a 15-minute live classical Indian music performance on sitar. After the experience, you will be asked to take part in a brief demographic questionnaire and a I5-minute exit interview.

In total, participating in this study will take 45-90 minutes depending on your post interview timeslot (approximate maximum wait period: 45 minutes).

As a research participant, your responsibilities would be to attend the musical performance and answer relevant questions in the form of a questionnaire and semi-structured interview. You will also have the option to review the written interpretation of the interview as created by the researcher through email correspondence.

\section{RISKS AND BENEFITS}

Risks may include some initial emotional discomfort in response to the musical experience. This may be a result of the aesthetic quality of the musical performance itself, as ragas can often create a mood of introspection.

You may experience potential benefits including the therapeutic benefit of a live improvised musical experience. This may include lowered stress and anxiety levels, as well as potential moments of introspection. You may also benefit from an introduction to a novel music, being the raga musical genre. You would have the option to access this musical genre after the research study.

\section{CONFIDENTIALITY}

We will gather the following information as part of this research: recorded and transcribed interviews in which you describe your experience of the musical performance; a brief demographic questionnaire will also be given to you to complete. 
By participating, you agree to let the researcher have access to your demographic information provided in the brief questionnaire, as well as information on your experiences of a live musical raga performance. The latter information will be obtained from semi-structured interviews. Interviews will be audio-recorded and transcribed.

No one will be allowed access to the information, except people directly involved in conducting the research. The information will be only used for the purposes of the research described in this form.

The information gathered will be identifiable; this means that it will have your name directly on it.

We will protect the information by encrypting files with password protection to which only the researcher and research advisor will have access. Any hardcopy material will be in a file and locked at Concordia University.

It is possible that results of research may be published. However, it will not be possible to identify you in the published results.

By agreeing to participate in the study you are automatically bound by a confidentiality agreement prohibiting any disclosure outside the group session of any other participant's identity and anything discussed.

You understand that transcriptions and research results may be used in presentations to educate other music therapists about the research findings and to benefit future music therapy practice.

We will destroy the information 5 years after the end of the study.

\section{E. CONDITIONS OF PARTICIPATION}


You do not have to participate in this research. It is purely your decision. If you do participate, you can stop at any time. This includes leaving during the musical performance or discontinuing the interview. You can also ask that the information you provided not be used, and your choice will be respected without prejudice. If you decide that you don't want us to use your information, you must tell the researcher anytime up until 2 weeks after the interview.

There are no negative consequences for not participating, stopping in the middle, or asking us not to use your information.

\section{F. PARTICIPANT'S DECLARATION}

I have read and understood this form. I have had the chance to ask questions and any questions have been answered. I agree to participate in this research under the conditions described.

NAME (please print)

SIGNATURE

DATE

If you have questions about the scientific or scholarly aspects of this research, please contact the researcher. Their contact information is on I. You may also contact their faculty supervisor.

If you have concerns about ethical issues in this research, please contact the Manager, Research Ethics, Concordia University, 5 I4.848.2424 ex.748I or oor.ethics@concordia.ca 
Appendix C

Brief Demographic Questionnaire

\section{Brief Demographic Questionnaire}

I. Please identify your age:

2. What is your current gender identity?

(e.g., male, female, trans man, trans woman, genderqueer/gender non-conforming)

3. Please state the ethnicity you identify with:

(e.g., African American, Native American, Asian, White, etc.)

4. What is/are your primary language(s)?

5. Please identify your primary occupation(s):

(e.g., student, health care worker, artist, construction work, etc.)

6. What style(s) of music or artist(s) do you feel deeply connected to?

(e.g., rock, gospel, jazz, reggae, classical, rap/hip hop, etc.) 
Appendix D

Guided Breathing Relaxation Script

\section{Guided Breathing Relaxation Script Preparation:}

Take a few moments to get as comfortable as possible in the chair. As you get comfortable try to make your body symmetrical...feet on the floor, arms either in lap or loosely at each side... Feel the support of the chair for your neck, shoulders...back, hips....and under the legs. Allow your body to sink into the chair, knowing that you are physically supported. You may choose to gently close your eyes, or to maintain a soft gaze towards the floor.

\section{Induction:}

Slowly become aware of your breathing... Notice what your breathing is like... It might be quite fast, or irregular... Notice the movement in your chest as you take in the breath... and as you release all other air from your chest... Notice how your body is feeling...you might feel your body is lighter, or it might be heavier...both these feelings are fine...gradually allow yourself to take deeper breaths....gently taking in the breath, gently releasing the breath... allowing the breath to fall into its own natural pattern... As you breath in...feel energized and as you breath out, feel relaxed... Feel the body fully and deeply relaxed... and now become aware of the music...

\section{Return to an Alert State:}

The music has finished...Become aware of the sounds around you...the sounds inside the room, and the sounds outside of the room...Become aware of the room we are in... and the people with you in the room... Begin to move your body, stretch out your arms... and legs... Take a deep breath... and release (the therapist might model an audible release of breath)... And when you are ready, open your eyes.

Adapted from pp. 96-99-100 in: Grocke, D., \& Wigram, T. (2007). Receptive methods in music therapy: Techniques and clinical applications for music therapy clinicians, educators and students. London, UK: Jessica Kingsley. 
Appendix E

Post-Experience Interview Questions Guideline

\section{Post-Experience Interview Questions Guidelines}

I. What was your general experience of the musical performance?

2. Were there any emotional or sensory changes for you during the experience?

3. Were there any emotional or sensory changes after the experience?

4. Did the music remind you of anything?

5. Did the music elicit any imagery memories or insights?

6. Was this an experience you would take part in again in the future should there be an opportunity. 